Article

\title{
Thermally Induced Structural Transitions of Nylon 49 as a New Example of Even-Odd Polyamides
}

\author{
Cristian Olmo ${ }^{1}$, Maria Teresa Casas ${ }^{1}$, Juan Carlos Martínez ${ }^{2}$, Lourdes Franco ${ }^{1,3, * \text { (D) }}$ \\ and Jordi Puiggalí 1,3,* \\ 1 Chemical Engineering Department, EEBE, Polytechnic University of Catalonia, Building I.2, C/Eduard \\ Maristany 10-14, 08019 Barcelona, Spain; olmocristian@gmail.com (C.O.); m.teresa.casas@upc.edu (M.T.C.) \\ 2 ALBA Synchrotron Light Facility, Carrer de la llum 2-26, Cerdanyola del Vallès, 08290 Barcelona, Spain; \\ guilmar@cells.es \\ 3 Research Center for Multiscale Science and Engineering, Polytechnic University of Catalonia, \\ C/Eduard Maristany 10-14, 08019 Barcelona, Spain \\ * Correspondence: lourdes.franco@upc.edu (L.F.); Jordi.Puiggali@upc.edu (J.P.); Tel.: +34-93-401-5649 (J.P.)
}

Received: 21 January 2018; Accepted: 14 February 2018; Published: 16 February 2018

\begin{abstract}
Crystalline morphology and structure of nylon 49 have been studied by means of optical and transmission electron microscopies, and X-ray diffraction. Rhombic crystals were characteristic of crystallization from glycerin dilute solutions, although the final morphology was dependent on the crystallization temperature. In any case, a single electron diffraction pattern was always obtained, being characteristic a $2 \mathrm{~mm}$ symmetry and reflections at spacings that were indicative of a projected rectangular unit cell with hydrogen bonds established along two planar directions (i.e., the diagonals of the unit cell), as it was determined from related polyamides. Crystallization from the melt gave rise to negative birefringent spherulites with a morphology (axialitic, speckled or ringed) that was dependent on the crystallization temperature. Kinetic analysis indicated that melt crystallization took place according to two growth mechanisms (Regimes II and III), which reflect distinct secondary nucleation rates. A complex polymorphic behavior on heating and cooling processes was evidenced by real time synchrotron experiments, being determined an intermediate crystalline structure as well as the typical pseudohexagonal arrangement associated to the Brill transition. Polymorphic transitions were highly dependent on the initial crystalline structure, being enhanced the structural transition from the low temperature structure to the intermediate one when traces of the latter were initially present. Calorimetric and infrared studies supported also the detected thermal transitions of nylon 49.
\end{abstract}

Keywords: polyamides; thermal transitions; hydrogen bonds; lamellar morphology; spherulites; synchrotron radiation; crystalline structure

\section{Introduction}

Aliphatic polyamides (nylons) are the first synthetic and semicrystalline polymers that displayed outstanding mechanical and thermal properties to be used as fibers and engineering thermoplastics [1,2]. Nylons are nowadays employed in a wide range of applications that mainly cover the textile, and automotive industries. The high performance of polyamides is a consequence of the strong intermolecular interactions that can be established between their constitutive $\mathrm{NH}$ and $\mathrm{CO}$ groups. Nylons are often classified according to the type of monomers implied in the polymerization, being distinguished between those obtained from a single monomer (i.e., $\mathrm{AB}$ polymers prepared by ring opening polymerization of lactams or alternatively by condensation of $\alpha$-amino acids or their derivatives) and those obtained from two monomers (AABB polymers prepared by the polycondensation of a diamine and a dicarboxylic acid or their derivatives). Such polymers are usually named as nylons $n$ and nylons $n$ 
$m$, being $n$ and $m$ indicative of the number of carbon atoms of the respective monomers. Final properties of nylons are logically dependent on the density of amide groups (i.e., the specific values of $n$ and $m$ ), but also on the crystalline structure. This structure should correspond to a minimum of the packing energy and consequently is governed by the formation of hydrogen bonds, keeping a practically linear geometry, between all constitutive amide groups. In this sense, the parity of the number of carbon atoms of the different monomers (i.e., odd or even $n$ and $m$ values) plays a remarkable influence on structure and properties. Nylon 6, nylon 11, nylon 12, nylon 6 6, nylon 610 and nylon 612 are specifically the aliphatic polyamides with higher commercial applications [1].

In general, the structure of such commercial nylons is based on the stack of sheets composed of hydrogen bonded molecular chains that could be in a parallel, antiparallel (e.g., even nylons) or both (e.g., odd nylons) dispositions, and had a practically all trans molecular conformation $[3,4]$. The antiparallel arrangement was postulated to be preferred for the odd nylons [5], while for centrosymmetric even-even nylons both dispositions are equivalent. Weak van der Waals forces are established between the consecutive hydrogen bonded sheets, being the packing energy optimized by a shift along both the single hydrogen bonding direction and the chain axis direction. This displacement may be progressive or recuperative giving rise to the well-known $\alpha$ and $\beta$ structures, respectively. The corresponding X-ray fiber diffraction patterns of such crystalline forms are characterized by the presence of two strong equatorial reflections associated with intrasheet and intersheet spacings (at 0.440 and $0.380 \mathrm{~nm}$, respectively) and a meridional or off-meridional orientation of reflections associated to the chain repeat for recuperative and progressive shears, respectively. Experimental limitations of fiber $\mathrm{X}$-ray diffraction analyses (broad and scarce number of reflections) induced to use other approximations to confirm the structural models. Force field calculations [6] and resolution of small model compounds by direct methods [7] can be mentioned.

Even nylons with many carbon atoms (e.g., nylon 12) crystallize according to a pseudohexagonal packing (defined by one or two close equatorial reflections in the $0.420-0.400 \mathrm{~nm}$ range), a deviation towards skew conformations for torsional angles of methylene-amide bonds, and a tilting of amide groups from the plane defined by the methylene carbon atoms [8]. In this way, hydrogen bonds become established between parallel chains and along a single direction that becomes outside the sheet plane defined by the methylene groups. This arrangement $(\gamma$ form $)$ is also found as a polymorphic form of even nylons with a medium length of its polymethylene segment (e.g., nylon 6 [9]), and was also postulated for odd-odd nylons due to impossibility to form a good hydrogen bonding geometry between chains having an all trans conformation [10]. The high applied interest of the indicated conventional polyamides have involved a considerable structural research, which is complex due to the indicated variety of molecular arrangements and molecular conformations that deals to polymorphic structures as it is the case of nylon 11 [11].

Thermal induced structural transitions are also a common characteristic observed for conventional nylons displaying the indicated $\alpha / \beta$ forms. In this way, equatorial reflections gradually merge into a single peak indicative of a pseudohexagonal arrangement at the named Brill temperature. This transition seems reversible but shows a hysteresis effect since it took place at a lower temperature on cooling. Understanding of Brill transition is problematic and different interpretations have been postulated [12-18]. In this way, it has been proposed an increased mobility of methylene groups that lead to a pseudohexagonal packing or alternatively the disruption of the initial hydrogen bonds (note that they are established along a single direction for $\alpha, \beta$ and $\gamma$ forms) to form new interactions randomly distributed along three planar directions at $120^{\circ}$.

New structures have also been determined for nylons having special units such as monomethylendiamine, malonamide and glycine. In these cases, a single methylene group is placed between two amide groups causing distinctive conformational preferences that lead to structures with a single (nylons $1 n$ [19]), double (nylons $n 3$ [20]) and three (nylons $2 / n$ [21]) coplanar hydrogen-bond orientations. Such structures were peculiar and consequently were also corroborated by the study of small model compounds [22-24]. 
Structures having two hydrogen bond orientations have also been postulated for several odd-even (e.g., nylons 56 [25], 510 [26], 92 [27], 1110 [28], 1112 [29] and 136 [30]) and even-odd (e.g., nylons 65 [31], 125 [32], 613 [33], 47 [34], 69 [35,36] and 89 [37]) nylons having longer polymethylene sequences (i.e., without a single methylene). In this case, new structures were a consequence of the impossibility to establish correct hydrogen bond interactions when odd diamides having extended conformations were involved as will then be explained in more detail. The interest on the study of odd derivatives is nowadays increasing due to two main points: (a) The necessity to produce polymers from renewable resources that could substitute fossil-based materials [38-41]. In this sense, nylons 5 6 [42-45], 69 [46] and 136 [30] are gaining attention. (b) The odd numbered polyamides may display ferroelectric properties $[47,48]$ and in particular the peculiar structure of nylon 69 has been considered to get polymers with piezoelectric activity [46].

The structural versatility of polyamides gave rise to a wide variety of spherulitic morphologies for a given polymer, being still unclear the drastic change with crystallization temperature of physical properties such as the birefringence sign. Therefore, it has been postulated that lamellar crystal growth inside spherulites varied and specifically conventional nylons gave rise to positive or negative spherulites depending if hydrogen bonds had a radial or tangential orientation, respectively [49,50]. Obviously, complexity increased for structures having two hydrogen bond orientations as it is the case of odd derivatives [51]. Lately, efforts have been focused to relate morphological evidence with structural changes induced by temperature for different even-odd polyamides (i.e., nylons 47 [34] and 69 [36]). Interestingly, properties were dependent on the edge-on and flat-on disposition of constitutive lamellae, displaying in the last case reversible changes on birefringence with temperature as a consequence of polymorphic transitions.

Nylon 49 corresponds to a scarcely studied even-odd polyamide that has an intermediate composition of those recently considered (i.e., the total number of carbon atoms is 13 instead of 11 (nylon 4 7) or 15 (nylon 6 9)). The present work is focused on the comprehension of four aspects: (a) characterization of the low temperature predominant form from the study of structure and morphology of single crystals; (b) study of thermally induced phase transformations on heating and cooling processes by means of real time synchrotron experiments and having special consideration on the occurrence of intermediate crystalline structures; (c) evaluation of the influence of the sample preparation process on the crystalline structure and the derived thermal induced structural transitions; and (d) study of spherulites developed at different crystallization temperatures, considering morphology, properties and crystallization kinetics.

\section{Experimental Section}

\subsection{Materials and Synthesis of Nylon 49}

All reagents and solvents were purchased from Sigma-Aldrich (Sant Louis, MO, USA) and used without purification. Nylons 49 was synthesized by interfacial polycondensation of azeloyl dichloride with 1,4-diaminobutane. To this end, $15 \mathrm{mmol}$ of the dichloride were dissolved in $75 \mathrm{~mL}$ of dry carbon tetrachloride and vigorously stirred while $75 \mathrm{~mL}$ of an aqueous solution containing $35 \mathrm{mmol}$ of 1,4-diaminobutane and $6.4 \mathrm{~g}$ of sodium carbonate was dropwise added. After addition was complete, stirring was kept for $30 \mathrm{~min}$ and then the powdered polymer was recovered by filtration, washed successively with water, ethanol and ethyl ether before drying in a vacuum desiccator at $60^{\circ} \mathrm{C}$. After that, it was purified by precipitation, by adding water to a dilute formic acid solution.

\subsection{Measurements}

Molecular weights of synthesized samples were determined by gel permeation chromatography (GPC). A Shimadzu LC-8A cromatograph (Shimadzu, Tokyo, Japan) equipped with an Empower computer program (Waters) was employed together with a PL HFIP gel column (Polymer Lab, Agilent Technologies Deutschland $\mathrm{GmbH}$, Böbligen, Germany)) and a refractive index detector RID-10A (Shimadzu, Tokyo, Japan). Molecular weights were calibrated using polymethyl methacrylate standards. 
Infrared absorption spectroscopic data were acquired with a FTIR 4100 Jasco spectrometer (Jasco International Co. Ltd., Tokyo, Japan) dotted with attenuated total reflection (ATR) (Specac model MKII Golden Gate. A heated Diamond Top-Plate was employed to study thermal induced transition.

${ }^{1} \mathrm{H}$ nuclear magnetic resonance (NMR) spectra were recorded on A Bruker AMX-300 spectrometer (Bruker Co., Bremen, Germany) at $25.0{ }^{\circ} \mathrm{C}$ operating at $300.1 \mathrm{MHz}$ and $25{ }^{\circ} \mathrm{C}$ was used to record ${ }^{1} \mathrm{H}$ NMM spectra. A mixture of deuterated chloroform and trifluoroacetic acid (9:1) was employed as solvent. Tetramethylsilan was added as internal reference.

Differential scanning calorimetric data were recorded with a TA instrument Q100 series (New Casttle, DE, USA) equipped with a refrigerated cooling system. Measurements were carried out with samples weighting approximately $5 \mathrm{mg}$ and under a flow of dry nitrogen. Thermal characterization involved: a first heating run $\left(20^{\circ} \mathrm{C} / \mathrm{min}\right)$ of the as-synthesized sample, a cooling run $\left(10^{\circ} \mathrm{C} / \mathrm{min}\right)$ after keeping the sample in the melt state for $3 \mathrm{~min}$ to erase thermal history and a subsequent heating run $\left(20^{\circ} \mathrm{C} / \mathrm{min}\right)$ to determine the behavior of a non-isothermally crystallized sample.

Thermogravimetric (TGA) and differential thermogravimetric (DTGA) data were acquired with a Q50 thermogravimetric analyzer of TA Instruments (New Casttle, DE, USA) under a flow of dry nitrogen with approximately $5 \mathrm{mg}$ samples and at a heating rate of $20^{\circ} \mathrm{C} / \mathrm{min}$.

Samples for optical microscopy observations were prepared from small sections of melt-crystallized films, which were subsequently pressed between cover slides, inserted in a hot stage, heated a $10^{\circ} \mathrm{C}$ higher than its melting point for $3 \mathrm{~min}$ and quickly cooled to the selected isothermal crystallization temperature. A Zeiss Axioscop 40 Pol light polarizing microscope (Carl Zeiss, Göttingen, Germany) was employed to measure the spherulite groth rate, while temperature was controlled with a Linkam system having a THMS 600 heating and freezing stage connected to an LNP 94 liquid nitrogen cooling system (Linkam Scientific, Tadworth, UK). A Zeiss AxiosCam MRC5 digital camera (Carl Zeiss, Göttingen, Germany) was employed to get micrographs at appropriate time intervals. Sign of spherulite birefringence was determined inserting a first-order red tint plate between crossed polarizers.

Lamellar crystals of nylon 49 were obtained by isothermal crystallization in dilute (ca. $0.1 \mathrm{mg} / \mathrm{mL}$ ) glycerin solutions at temperatures between 90 and $130{ }^{\circ} \mathrm{C}$. In all cases, the crystals were recovered from the mother liquor by centrifugation, repeatedly washed with $n$-butanol and deposited on carbon-coated grids, which were shadowed with Pt-Carbon at an angle of $15^{\circ}$ for bright field observations.

A Philips TECNAI 10 electron microscope (Philips Electron Optics, Eindhoven, The Netherlands) was used and operated at 80 and $100 \mathrm{kV}$ for bright field and electron diffraction modes, respectively. Selected area electron diffraction patterns and bright field micrographs were taken with a SIS MegaView digital camera (Olympus Soft Imaging Systems Inc., LLC, Lakewood, WA, USA). Diffraction patterns were internally calibrated with gold $\left(\mathrm{d}_{111}=0.235 \mathrm{~nm}\right)$.

The real-time variable temperature synchrotron study was carried out on beamline BL11-NCD at ALBA (Cerdanyola del Vallès, Barcelona, Spain) by using a wavelength of $0.100 \mathrm{~nm}$ and a WAXD LX255-HS detector from Rayonix. Polymer samples were confined between Kapton films and then held on a Linkam hot stage with temperature control within $\pm 0.1^{\circ} \mathrm{C}$. WAXD profiles were acquired during heating and cooling runs in time frames of $20 \mathrm{~s}$ and rates of $10^{\circ} \mathrm{C} / \mathrm{min}$. WAXD diffraction patterns were calibrated by means of a geometrical calibration process of a well-known sample (standard $\mathrm{Cr}_{2} \mathrm{O}_{3}$ ). Diffraction profiles were normalized to the beam intensity and corrected considering the empty sample background.

\section{Results and Discussion}

\subsection{Chemical Characterization}

Nylon 49 was obtained with a yield of $60 \%$, polydispersity index of 2.5 and number average molecular weight of 21,000, as determined by GPC (Figure 1a). Index was slightly higher than theoretically expected from Flory's theory (i.e., 2.5 with respect to 2.0), suggesting the presence of a small ratio of oligomers. FTIR and ${ }^{1} \mathrm{H}$ NMR spectra of the synthesized nylon are given in Figure $1 \mathrm{~b}, \mathrm{c}$, respectively. 
Spectra were fully consistent with the anticipated chemical constitution. Specifically, infrared spectra showed the characteristic absorption bands of amide and methylene groups at: $\approx 3291 \mathrm{~cm}^{-1}$ (Amide A, $\mathrm{N}-\mathrm{H}$ stretching), $\approx 3066 \mathrm{~cm}^{-1}$ (Amide B, overtone of Amide II), 2927 and $2851 \mathrm{~cm}^{-1}$ (asymmetric and symmetric $\mathrm{CH}$-stretching bands), $\approx 1633 \mathrm{~cm}^{-1}$ (Amide I, $\mathrm{C}=\mathrm{O}$ stretching), $\approx 1539 \mathrm{~cm}^{-1}$ (Amide II, C-N stretching and CO-N-H bending), $\approx 940 \mathrm{~cm}^{-1}$ (Amide IV, C-CO stretch) $\approx 721 \mathrm{~cm}^{-1}\left(\mathrm{CH}_{2}\right.$ waging), and $\approx 684 \mathrm{~cm}^{-1}$ (Amide $\mathrm{V}, \mathrm{N}-\mathrm{H}$ out of plane bending). ${ }^{1} \mathrm{H}$ NMR spectra were characterized by peaks at: $8.56 \mathrm{ppm}(\mathrm{NH}$, broad, $2 \mathrm{H}), 3.50 \mathrm{ppm}\left(\mathrm{NHCH}_{2}\right.$, broad, $\left.4 \mathrm{H}\right), 2.60 \mathrm{ppm}\left(\mathrm{COCH}_{2}\right.$, triplet, $\left.4 \mathrm{H}\right), 1.69 \mathrm{ppm}$ $\left(\mathrm{NHCH}_{2} \mathrm{CH}_{2}\right.$, broad, $4 \mathrm{H}+\mathrm{COCH}_{2} \mathrm{CH}_{2}$, broad, $\left.4 \mathrm{H}\right)$ and 1.34 ppm $\left(-\left(\mathrm{CH}_{2}\right)_{3}-\right.$, broad, $\left.6 \mathrm{H}\right)$. Nylon 49 had a high thermal stability as demonstrated by the thermogravimetric curves displayed in Figure $1 \mathrm{~d}$. The onset degradation temperature was close to $290^{\circ} \mathrm{C}$, being the decomposition process defined by a single step with a maximum DTGA peak at $448^{\circ} \mathrm{C}$. This stability appears highly important to discard any evidence of thermal degradation during the heating scans at which samples were submitted for the study of structural transitions.

a)

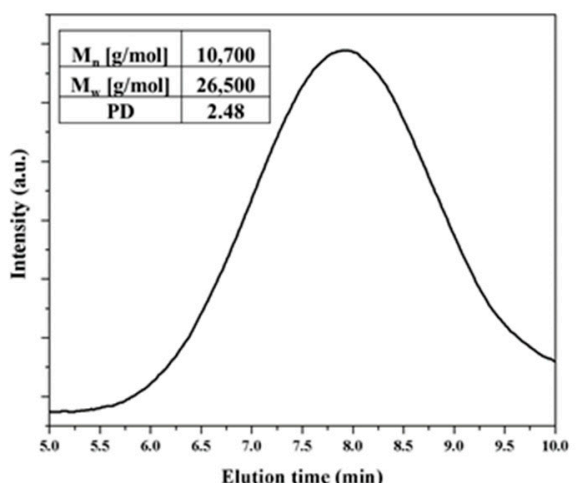

b)

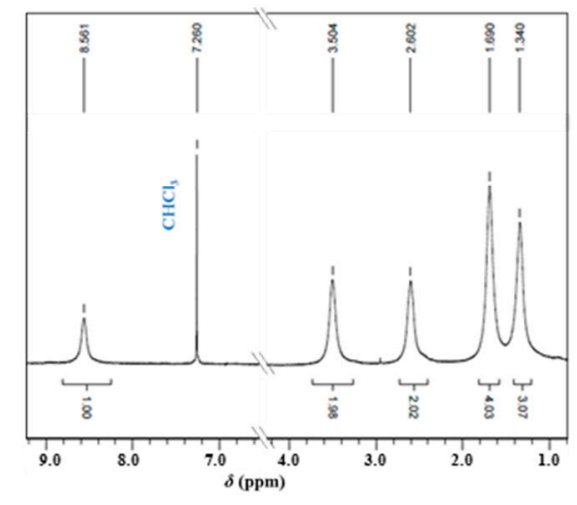

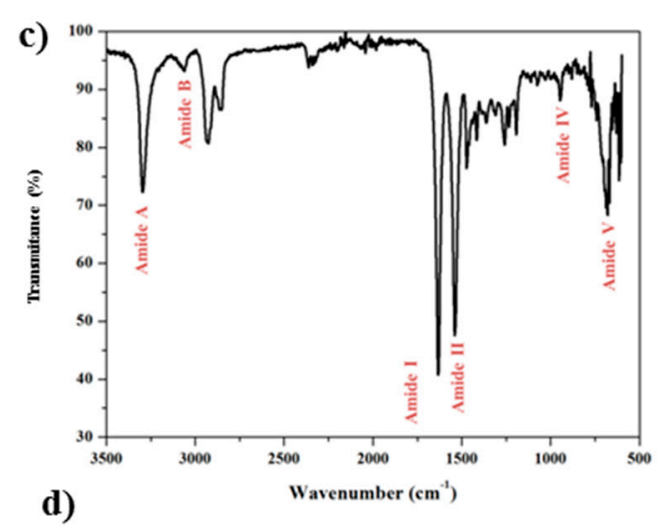

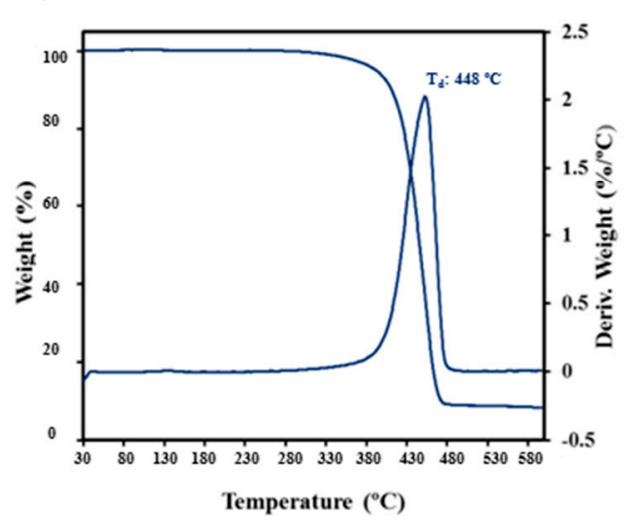

Figure 1. GPC chromatograph (a); FTIR spectrum (b); ${ }^{1} \mathrm{H}$ NMR spectrum (c); and TGA/DTGA thermogravimetric curves (d) of synthesized nylon 49.

\subsection{Morphology of Nylon 49 Single Crystals}

Crystals suitable for electron microscopy studies were obtained by isothermal crystallization from dilute solutions in glycerin. Their morphology varied depending on the conditions used for the preparation of samples and specifically on the selected temperature. Thus, crystallizations performed at temperatures higher than $90{ }^{\circ} \mathrm{C}$ rendered aggregates derived from a common nucleus having radial arms with well-defined extremities (Figure 2a). Crystals with different orientations could be detected (i.e., parallel, tilted and perpendicular to the film surface).

By contrast, planar aggregate structures were observed at temperatures close to $110{ }^{\circ} \mathrm{C}$. The morphology of constitutive lamellae was highly variable although rhombic crystals were predominant over lath shaped crystals (Figure 2b). Different irregularities were common and easily detected, such as the 
presence of highly serrated edges and even of striations and globules on the surface of crystals. The best lamellar crystals were attained at $120^{\circ} \mathrm{C}$ (Figure 2c). An obtuse angle of $12^{\circ}$ was measured accurately while the acute angle was less well defined $\left(\mathrm{ca} .50^{\circ}-53^{\circ}\right)$, and specifically the rhombic appearance was lost at higher temperatures (e.g., Figure $2 \mathrm{~d}$ for crystallization performed at $130^{\circ} \mathrm{C}$ ). Obtuse angles could be well recognized, whereas the elongated morphology gave rise to a significant deviation of the acute angle. In all cases, individual lamellae were about $9 \mathrm{~nm}$ thick, as estimated from their shadows in the micrographs. This low thickness value and the high molecular weight of the polymer clearly indicate that molecular chains were folded, as is well established for polymer lamellar crystals.
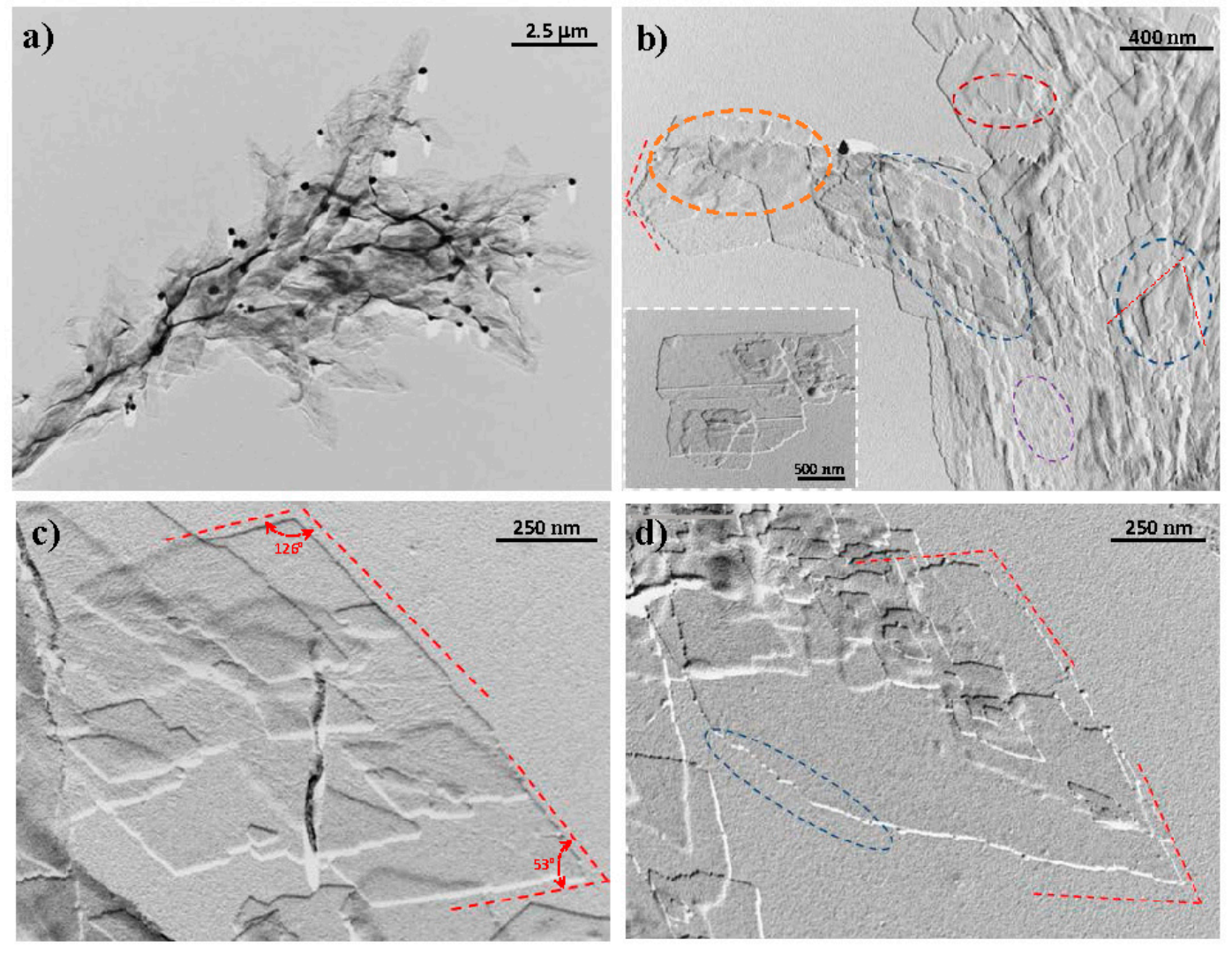

Figure 2. Transmission electron micrographs of nylon 49 crystals obtained from dilute glycerin solutions, illustrating the influence of crystallization conditions on morphology: (a) Arm of an spherulitic aggregate obtained at $90^{\circ} \mathrm{C}$. (b) Aggregates constituted by planar crystals obtained at $110^{\circ} \mathrm{C}$. Blue ellipsoid shows the presence of rhombic crystals whereas the orange ellipsoid and the inset point out the presence of lath shaped crystals. Serrated faces and globules are marked with garnet and violet ellipsoids, respectively. (c) Rhombic lamellar crystals obtained from crystallizations performed at $120^{\circ} \mathrm{C}$. Red dashed lines define the theoretical angles between growth faces. (d) Elongated lamellar morphologies obtained at $130{ }^{\circ} \mathrm{C}$. Dashed lines indicate the theoretical growth faces according to the expected rhombic morphology. Obtuse angles could be recognized although curved morphologies could also be detected (blue ellipsoid).

Electron diffraction patterns of the different nylon 49 crystals have the same features, indicating that a single structure was always obtained. However, crystals prepared from glycerin at $120^{\circ} \mathrm{C}$ gave the best pattern (Figure 3) because single crystals of adequate dimensions could be selected for diffraction. This pattern was characterized by a $2 \mathrm{~mm}$ symmetry with four and two prominent reflections at 0.385 and $0.430 \mathrm{~nm}$, respectively. The above symmetry was always observed, but no additional reflections with a variable intensity that could be associated with a twinned structure were detected, as is common in conventional nylons. Pattern resolution was up to $0.160 \mathrm{~nm}$ 
(i.e., 150 reflection) and allowed a rectangular unit cell with $a$ and $b$ dimensions of $0.430 \mathrm{~nm}$ and $0.860 \mathrm{~nm}$, respectively, to be determined. The angles between the indexed 110 and -110 reflections and between 110 and $1-10$ reflections were $126^{\circ}$ and $54^{\circ}$, respectively, in full agreement with the obtuse and acute angles observed in the bright field micrographs. Therefore, the lateral faces of rhombic crystals corresponded to 110 planes.

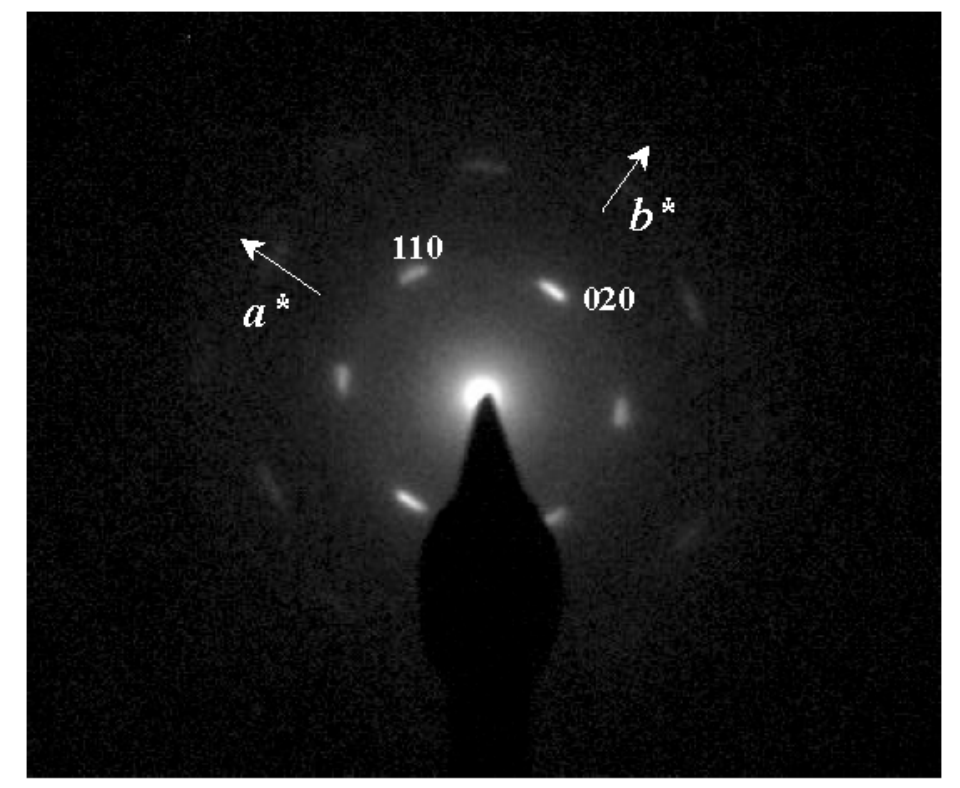

Figure 3. (a) Selected-area electron diffraction pattern of nylon 49 single crystals prepared from glycerin at $120^{\circ} \mathrm{C}$. Only the most intense $h k 0$ reflections are labeled. The pattern shows a clear $2 \mathrm{~mm}$ symmetry and reciprocal axes are labeled. (b) X-ray diffraction profile of a nylon 49 sample isothermally crystallized from diluted glycerin solution.

Diffraction data of solution crystallized nylon 49 samples agree with previous observations performed with different odd-even [25-30] and even-odd [3-37] nylons. In all these cases, hydrogen bonds were not well established between molecular chains having an extended conformation and along a single direction, as is typical of the sheet structure described for conventional nylons. Therefore, a different molecular arrangement involving the establishment of intermolecular hydrogen bonding interactions along two directions was postulated because it could justify the observed symmetry of the electron diffraction pattern. This structure implied minimum distortion of the zig-zag molecular conformation and was compatible with spacings similar to those reported for conventional $\alpha / \beta$ forms of conventional nylons.

Basically, the model is based on a slight deviation towards $150^{\circ}$ (or $-150^{\circ}$ ) of the two torsional angles vicinal to the odd diamide units, which allows all $\mathrm{NH}$ and $\mathrm{CO}$ groups of neighboring chains to be faced. The two amide groups of the odd unit rotated in opposite senses from the plane defined by the methylene carbon atoms, allowing the establishment of a good hydrogen-bonding geometry when neighboring chains became conveniently shifted along the chain axis direction (Figure 4). A monoclinic unit cell containing two molecular segments was derived and the chain axis projection corresponded to a rectangular unit cell, with the dimensions of the diagonals being in full agreement with the expected distances between hydrogen bonded chains. Nylon 92 is probably the clearest example of such structure due to its highly rich diffraction pattern and the existence of a highly rigid oxalamide unit in the molecular chain [32].

X-ray diffraction pattern (Figure 5) of the as synthesized sample showed two strong reflections at 0.429 and $0.375 \mathrm{~nm}$ that are associated to the molecular packing and correspond with those observed in the electron diffraction patterns. A 002 reflection at $0.711 \mathrm{~nm}$ (red ellipsoid) can also be detected and allows postulating a non-orthorhombic structure since this value is clearly lower than the calculated 
value for the chain repeat length from either an all trans conformation or a typical $\gamma$ form conformation ( 0.890 and $0.850 \mathrm{~nm}$, respectively).
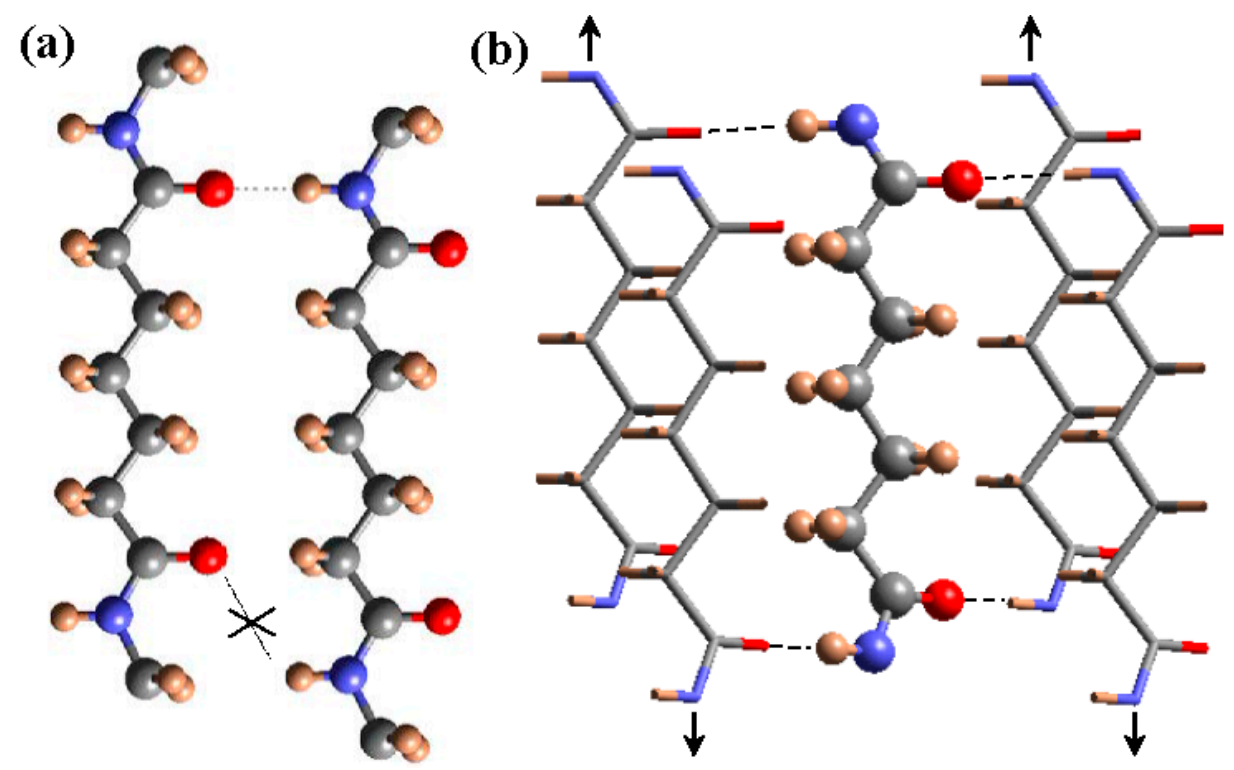

Figure 4. Scheme of the unfavorable hydrogen bonding geometry between odd carboxamide (i.e., pimelamide) units having an all-trans conformation (a); and the favorable interaction established according to the proposed structure where hydrogen bonds are established along two directions (b). For shake of clarity different representations are employed for the external and inner chains of the unit cell and a shorter dicarboxylic unit (i.e., pimelamide) has been considered. Arrows indicate the shift of neighboring chains with respect the central one. Color code: nitrogen, blue; oxygen, red; carbon, gray; hydrogen, brown. Reproduced with permission from [36], copyright 2015 Elsevier.

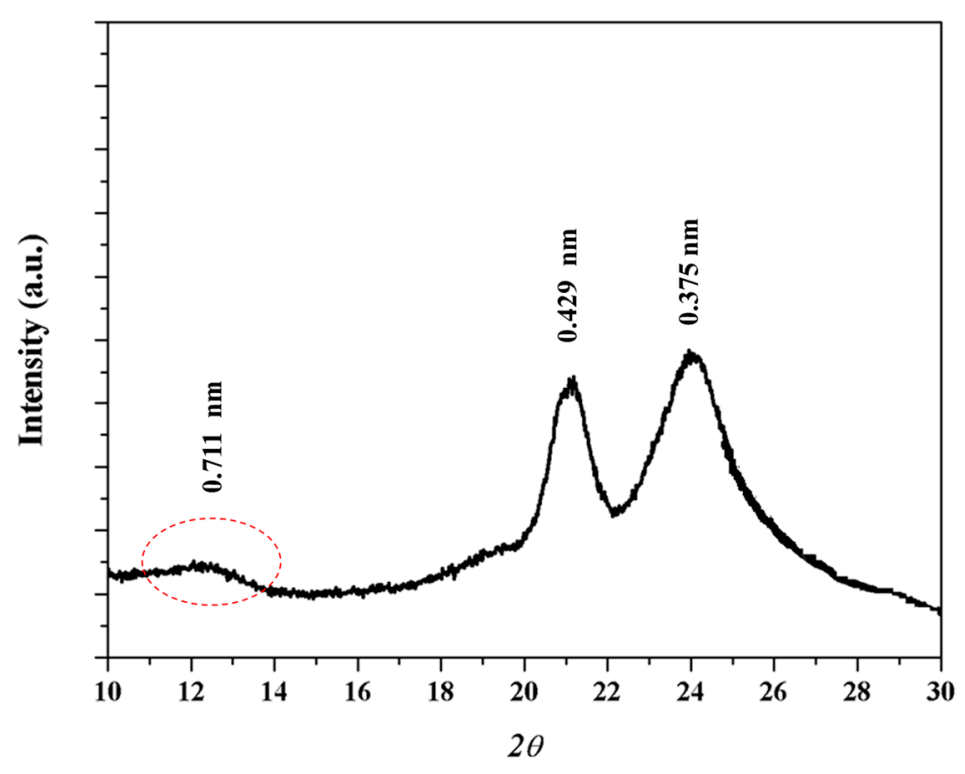

Figure 5. X-ray diffraction profile of as synthesized nylon 49 sample.

\subsection{Structural Transitions of Nylon 49 during Heating and Cooling Processes from Real Time WAXD Data}

The evolution of the X-ray diffraction pattern with increasing temperature is illustrated in Figure $6 \mathrm{a}$ for the two main peaks associated with the molecular packing. The sample recovered from synthesis displayed clear and well-distinguished peaks at $0.430 \mathrm{~nm}$ and $0.375 \mathrm{~nm}$, which correspond 
to the same crystalline form (named Form I), determined for the solution crystallized lamellar crystals. Minor differences are found for the spacing of the 110 reflection, which could be due to the different temperatures at which the crystalline structure was formed (i.e., $25^{\circ} \mathrm{C}$ and $120^{\circ} \mathrm{C}$ for precipitated and solution crystallized samples, respectively). Temperature evolution of diffraction profiles showed several remarkable features:

(a) The peak at $0.375 \mathrm{~nm}$ progressively shifted to higher spacings up to a maximum value of $0.410 \mathrm{~nm}$ (Figure 6b), whereas the spacing of the 020 reflection remained practically constant (i.e., $0.430 \mathrm{~nm}$ ). Basically, the $a$ parameter of the unit cell increased (i.e., from 4.30 to $4.67 \mathrm{~nm}$ ) while the $b$ parameter was constant. The projected unit cell therefore became distorted with increasing temperature, with a dilatation being observed in the (100) direction where neighboring chains were closer (i.e., $4.30 \mathrm{~nm}$ as opposed to $0.480 \mathrm{~nm}$ in the (110) direction). This change can be produced by a small change in the rotation angle between consecutive amide planes (i.e., from $53^{\circ}$ to $57^{\circ}$, as determined from basic geometry considerations). It should also be pointed out that the 110 spacing becomes 0.385 at temperatures close to $120^{\circ} \mathrm{C}$, a feature that is in full agreement with the electron diffraction data from lamellae crystallized at such temperature.

(b) Around $120^{\circ} \mathrm{C}$, a recrystallization phenomenon involving Form I can be detected (Figure 6a). This feature is clearer in Figure 7a, where the intensity of mean peak is displayed (see ellipsoid).

(c) At temperatures close to $195^{\circ} \mathrm{C}$ a new peak started to appear and reached its maximum intensity just before polymer melting. The spacing of the new reflection increased slightly from 0.418 to $0.423 \mathrm{~nm}$ and suggested the formation of the typical high temperature pseudohexagonal packing (named here Form III) that is achieved after the Brill transition. It is interesting that Form I reflections did not meet at high temperature, as is usually observed for conventional nylons. Profiles clearly suggest that Form I progressively disappeared and became the new Form III (see the intensities displayed in Figure 7a). Nevertheless, the transition is not completely clear due to the start of the melting process $\left(225^{\circ} \mathrm{C}\right)$, just when the Form III peak appears better defined.

a)

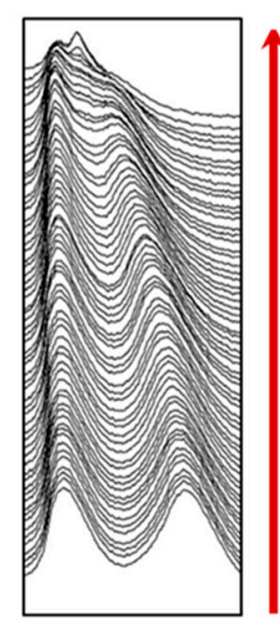

$q\left(\mathrm{~nm}^{-1}\right)$ b)

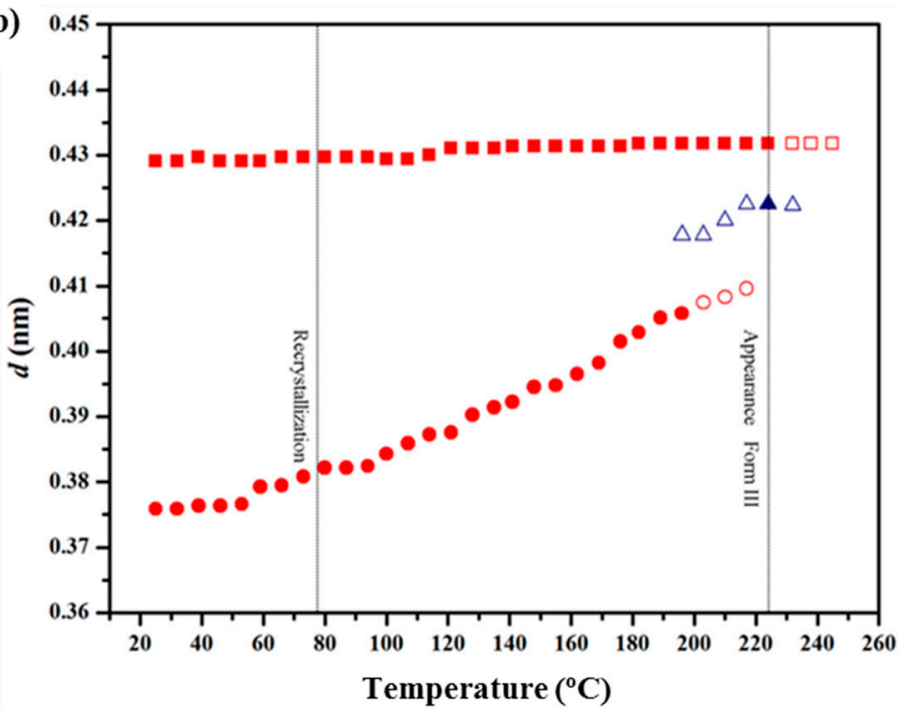

Figure 6. (a) Three-dimensional representation of WAXD profiles of a solution crystallized nylon 49 sample during heating $\left(10^{\circ} \mathrm{C} / \mathrm{min}\right)$ from room temperature to fusion; and $(\mathbf{b})$ evolution of the spacings of the two main reflections during the first heating. Full and empty symbols indicate well-defined and intuited reflections, respectively. The temperatures at which structural transitions occur are indicated with vertical lines. Reflections corresponding to Forms I and III are indicated in red and blue, respectively. 


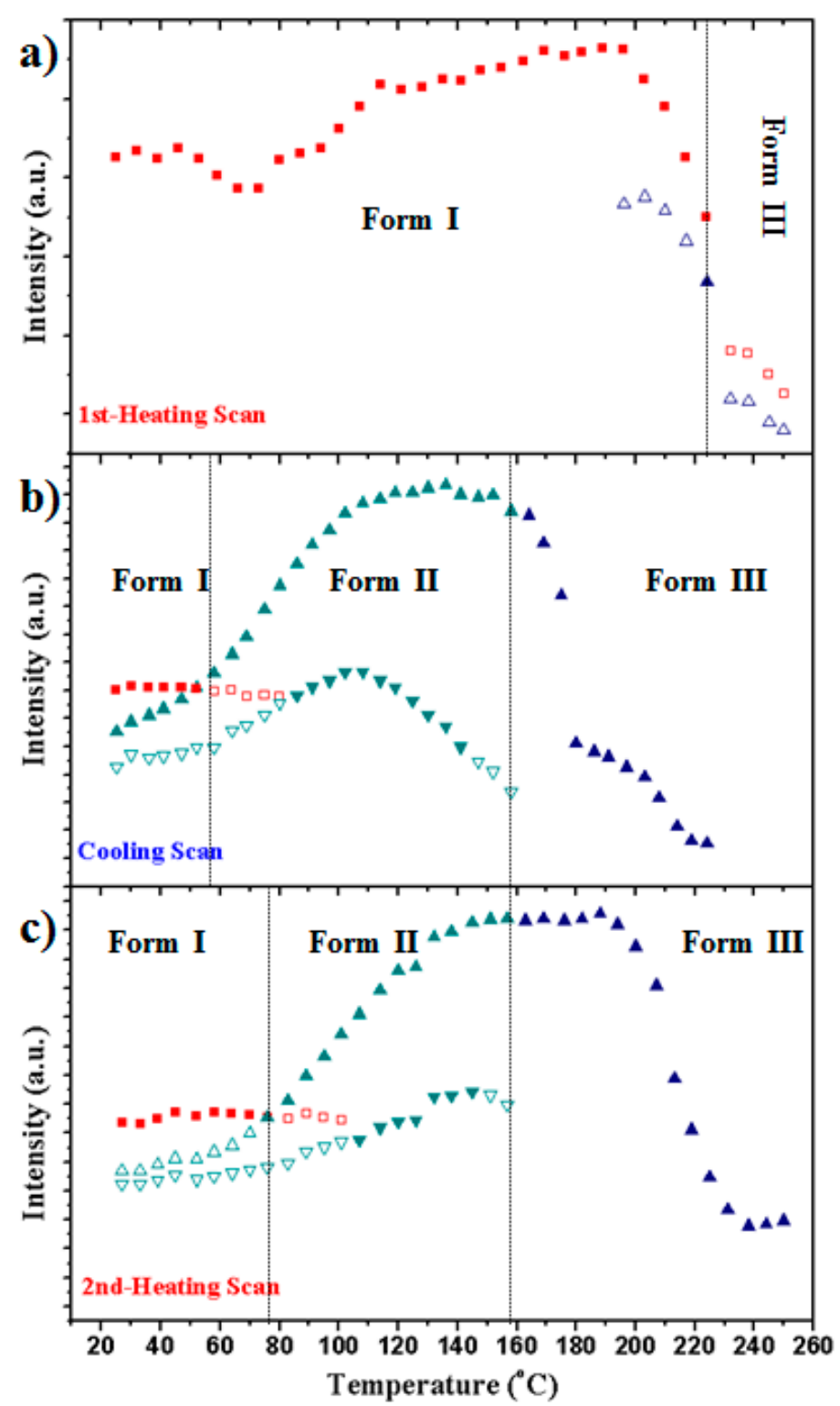

Figure 7. Temperature evolution of the intensity of the main peaks (for the clarity of representation the Form I peak at $0.375-0.410 \mathrm{~nm}$ is not plotted) during: the first heating (a); cooling (b); and second heating (c) processes. Full and empty symbols indicate well-defined and intuited reflections, respectively. The temperatures at which structural transitions occur are indicated with vertical lines. Reflections corresponding to Forms I, II and III are indicated in red, green and blue, respectively.

The evolution of X-ray diffraction profiles during cooling from the melt state is considerably more complicated because a new crystalline form (named Form II) appeared, as shown in the 3D profiles. The plot of spacings associated with the main observed reflections and the plot of intensity of representative reflections of each crystalline form, as shown in Figure 8a,b and Figure 7b, respectively.

The main features observed in the cooling process can be summarized as follows:

(a) The sample crystallized from the melt in the high temperature Form III, giving rise to a single peak at around $238{ }^{\circ} \mathrm{C}$, which spacing slightly decreased from 0.426 to $0.422 \mathrm{~nm}$ when temperature diminished from 230 to $162{ }^{\circ} \mathrm{C}$. This change corresponds to a simple cell contraction and is a reversible process with respect to the observed one during heating. The peak reached its maximum intensity around $162{ }^{\circ} \mathrm{C}$, suggesting that the primary crystallization process completely 
finished, which is in agreement with calorimetric (at the same cooling rate of $10^{\circ} \mathrm{C} / \mathrm{min}$ ) and optical microscopy observations as then will be shown. Furthermore, diffraction profiles supported, as also will be indicated, that the different kinds of spherulites formed in the $238-229{ }^{\circ} \mathrm{C}$ temperature range had the same Form III structure at the temperature where the micrographs were taken (i.e., when further structural transitions that took place on cooling were avoided).

(b) A peak shoulder around $0.410 \mathrm{~nm}$ could be envisaged when temperature decreased from $160{ }^{\circ} \mathrm{C}$, being clearly defined at $140{ }^{\circ} \mathrm{C}$. The splitting of the single reflection suggests a minor structural change since a pseudohexagonal packing is still detected (i.e., reflections appeared at $0.420-0.417 \mathrm{~nm}$ and $0.410 \mathrm{~nm}$ while a single reflection at $0.415 \mathrm{~nm}$ is expected for a hexagonal packing defined by a typical hydrogen bonding distance of $0.479 \mathrm{~nm}$ between neighboring chains).

(c) A dramatic decrease of the intensity of the two reflections associated to Form II is observed in the $130-60{ }^{\circ} \mathrm{C}$ temperature range while new reflections associated to Form I appeared. Profiles clearly demonstrated that a structural transition took place rather than a continuous divergence of reflections as commonly described for a Brill transition. Finally, and with respect to Form I reflections, it can be pointed out that the 110 reflection was again the most sensitive to the temperature change since its spacing decreased from 0.393 to $0.385 \mathrm{~nm}$ (a value that is in full agreement with electron diffraction patterns). Logically, structural transition was stopped when the glass transition temperature was reached (i.e., $60^{\circ} \mathrm{C}$ ) and consequently no further changes on the diffraction profiles were detected.
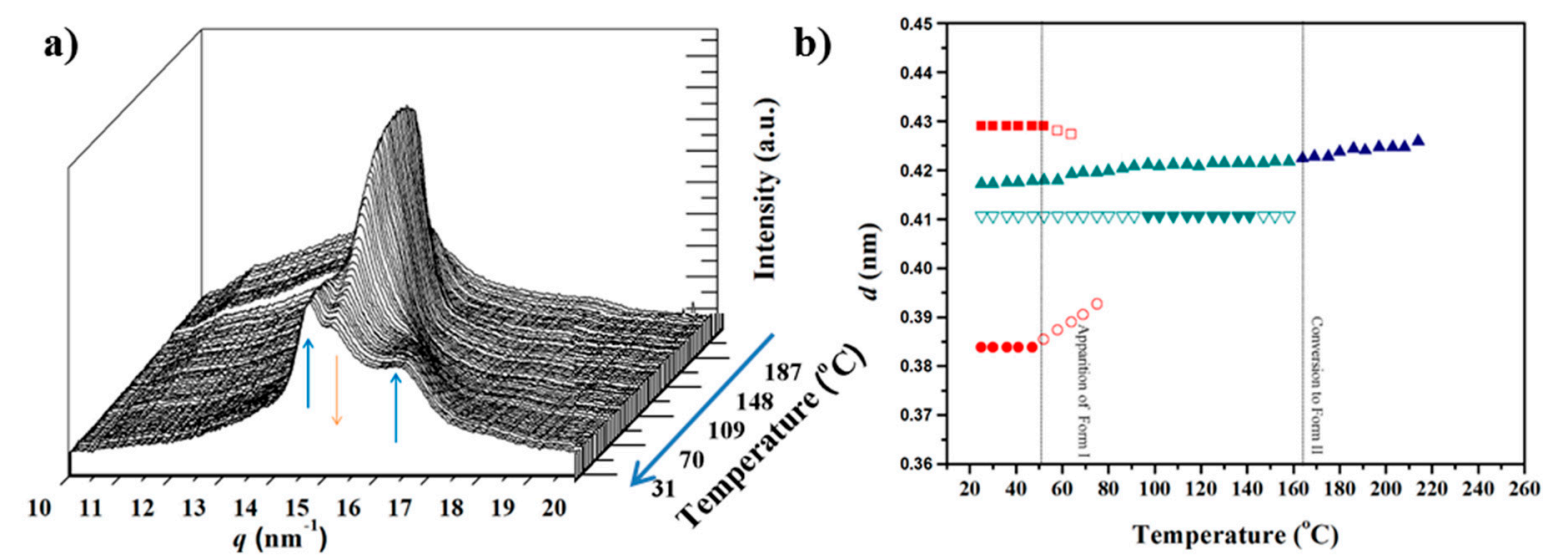

Figure 8. (a) Three-dimensional representation of WAXD profiles of nylon 49 during cooling $\left(10{ }^{\circ} \mathrm{C} / \mathrm{min}\right.$ ) from the melt to room temperature; and (b) evolution of the spacings of the two main reflections during the cooling run. Full and empty symbols indicate well-defined and intuited reflections, respectively. The temperatures at which structural transitions occur are indicated with vertical lines. Reflections corresponding to Forms I, II and III are indicated in red, green and blue, respectively.

Figure 9 compares the diffraction profiles of nylon 49 taken at room temperature for the solution and melt crystallized samples. In the first case, only the two characteristic peaks at $0.430 \mathrm{~nm}$ and $0.375 \mathrm{~nm}$ were detected with similar intensity. On the other hand, the second peak shifted to $0.385 \mathrm{~nm}$ while an additional highly intense peak at $0.417 \mathrm{~nm}$ appeared for the melt crystallized sample. The relative intensity between the two peaks associated with Form I also appeared clearly different in the profile of the melt crystallized sample because of the presence of the predominant peak of Form II. A profile taken during the cooling process is also given to emphasize the increase of Form I and the decrease of Form II during cooling, as well as the problematic presence of the shoulder associated with Form II (see ellipsoid and asterisk). Profiles also indicate the presence of an amorphous halo, which appears less intense in the solution crystallized sample and reflects the higher crystallinity of this sample (i.e., see dashed rectangles). 
Figure 10a,b shows the evolution of profiles and main spacing of a melt crystallized sample during heating. In this case, it is clear that Form I experiences a structural transition towards Form II in the interval temperature between 75 and $120^{\circ} \mathrm{C}$. This behavior clearly differs to the observed one during the first heating run, where Form I is kept up to fusion. It seems that the initial presence of Form II facilitates the polymorphic transition. That is to say, the initial Form II domains displayed a nucleating effect that facilitated the development of new Form II crystals. The plot showing the evolution of spacings (Figure 10b) is similar to that obtained during the cooling run (Figure 8b) although the transition between Forms II and I took place at slightly higher temperatures. It should also be pointed out that the maximum peak intensity during heating processes is observed at a temperature of $185-190{ }^{\circ} \mathrm{C}$, but it corresponds to different crystalline structures: Form I in the first heating run and Form III in the second one. This feature is again a clear indication of the dependence of the structural transition with the distribution of crystalline phases in the initial sample as then will be more extensively discussed.

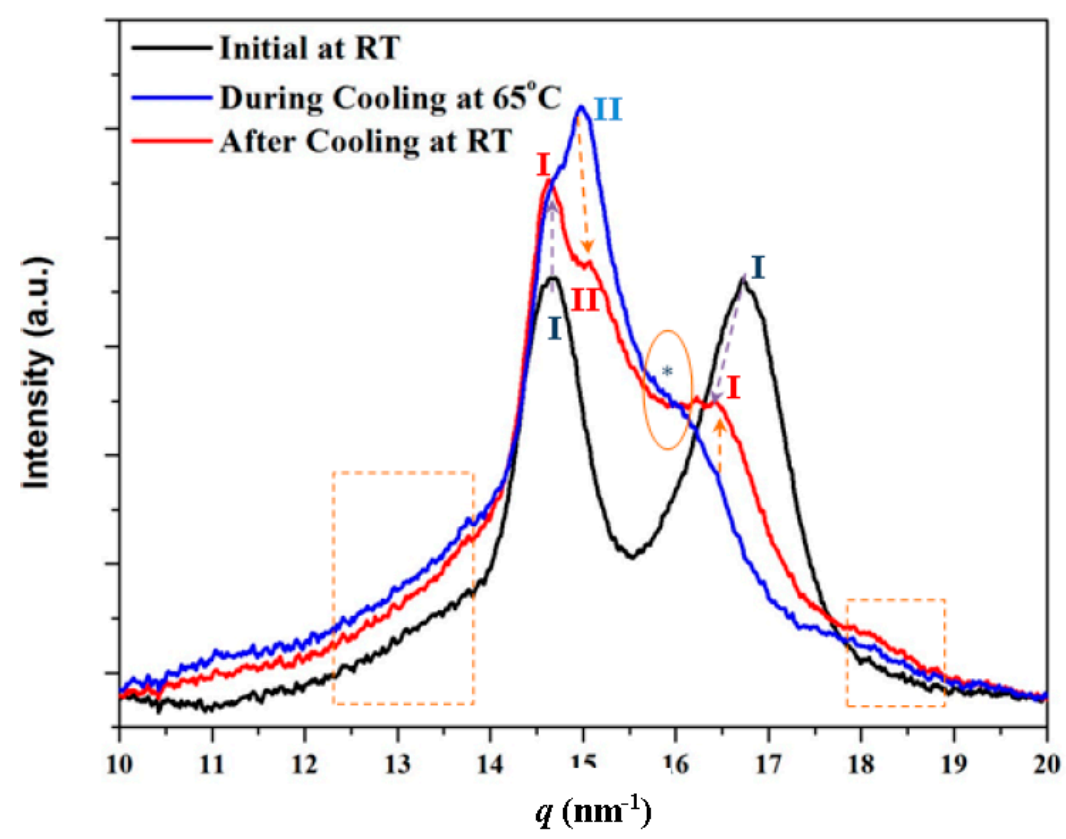

Figure 9. Diffraction profiles taken at room temperature for the solution (black) and melt (red) crystallized samples. Purple arrows compare the peaks associated with Form I. For the sake of completeness, a profile taken during cooling at $65^{\circ} \mathrm{C}$ (blue) is also given. Evolution during cooling of some Form I and Form II representative peaks is indicated by the orange arrows and the shoulder associated with Form II with the asterisk and the ellipsoid. Dashed rectangles indicate the regions where tails of the amorphous halo could be detected. 

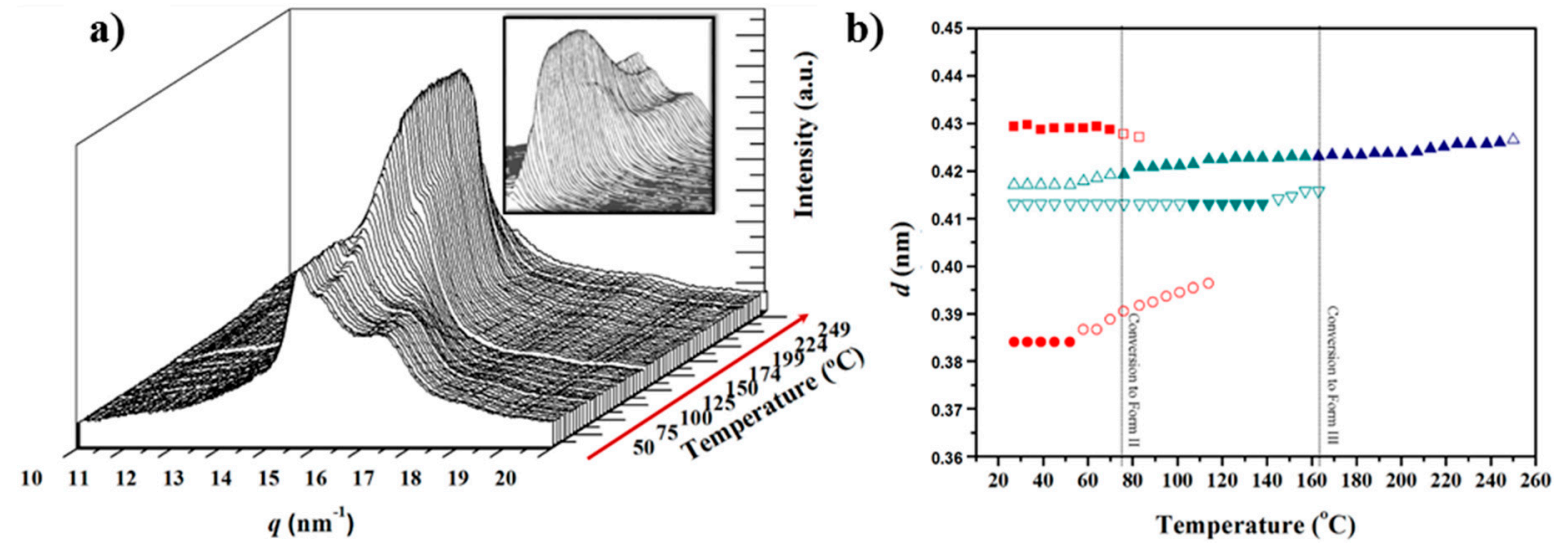

Figure 10. (a) Three-dimensional representation of WAXD profiles of a melt crystallized nylon 49 sample during the second heating $\left(10^{\circ} \mathrm{C} / \mathrm{min}\right)$ from room temperature to fusion. Insets show a different orientation to clarify the temperature evolution of the main reflections. (b) Evolution of the spacings of the main reflections during the cooling run. Full and empty symbols indicate well-defined and intuited reflections, respectively. The temperatures at which structural transitions occur are indicated with vertical lines. Reflections corresponding to Forms I, II and III are indicated in red, green and blue, respectively.

\subsection{FTIR Changes during Heating Processes}

FTIR spectra are sensitive to structural changes. Specifically, the region between 1560 and $1500 \mathrm{~cm}^{-1}$ was found to be very useful to follow the polymorphism of nylon 49 . The spectrum of the solution crystallized sample showed two minor bands at $1576 \mathrm{~cm}^{-1}$ and $1505 \mathrm{~cm}^{-1}$, together with a very broad band centered at $1535 \mathrm{~cm}^{-1}$, which is typically associated with the Amide II band (coupling of the C-N stretching mode with $\mathrm{N}-\mathrm{H}$ in plane bending mode) (Figure 11a). The intensity of all these bands increased on heating around a temperature of $95{ }^{\circ} \mathrm{C}$ as a consequence of the previously described cold crystallization process. The increase of the intensity of the Amide II band, together with temperature induced broadening, allowed several shoulders to be detected. Nevertheless, no remarkable change was observed until a temperature of $200{ }^{\circ} \mathrm{C}$ was reached, which was the maximum value that could be attained with the heater controller adapted to the ATR cell. Therefore, it can be concluded that no structural transition took place, in agreement with synchrotron data.

The sample was subsequently melted outside the ATR cell and then cooled at a rate of $10^{\circ} \mathrm{C} / \mathrm{min}$. The room temperature spectrum was well differentiated from those previously described since the Amide II band was clearly split, with two additional peaks appearing at $1540 \mathrm{~cm}^{-1}$ and $1524 \mathrm{~cm}^{-1}$ (Figure 11b). These peaks could be associated with Form II and had an increased intensity at high temperature while the intensity of the intermediate peak at $1534 \mathrm{~cm}^{-1}$ clearly increased during cooling, as expected for Form I. The temperature evolution of FTIR spectra indicates, again, a structural transition from Form II to Form I that took place in a wide temperature range during cooling. The spectra also showed a continuous increase of the intensity of the peak at $1505 \mathrm{~cm}^{-1}$, which could therefore not be associated with a defined structure since the observed evolution was always detected, independent of the predominant structure (Form I or II). 

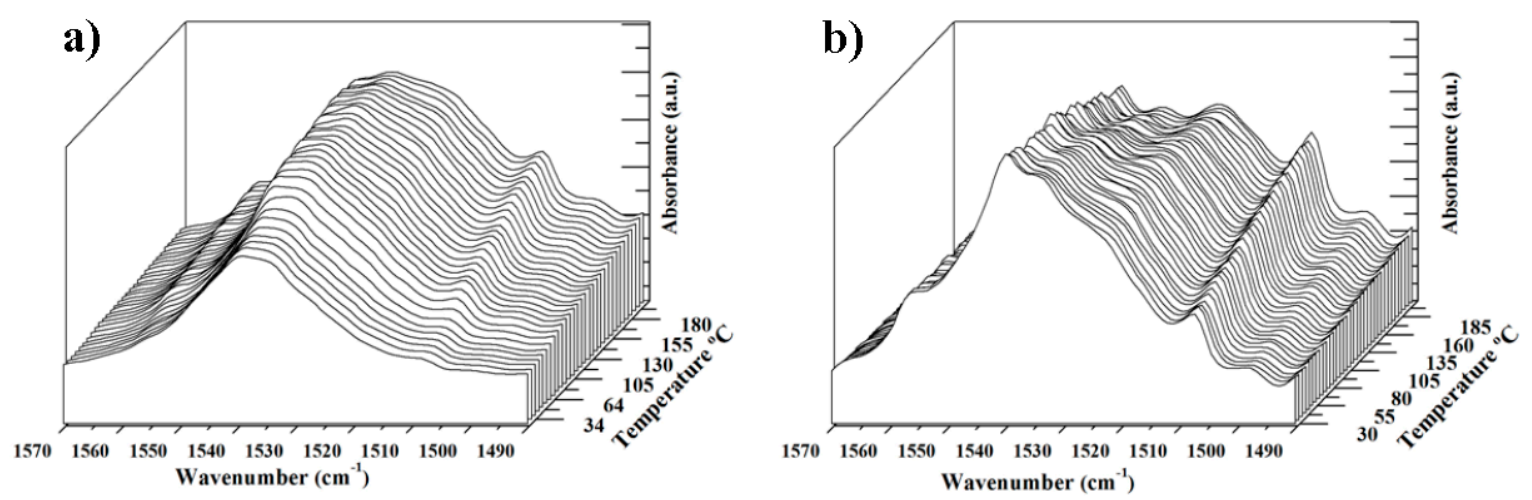

Figure 11. Temperature evolution of the $1570-1485 \mathrm{~cm}^{-1}$ region of the FTIR spectra of: solution crystallized (a); and melt crystallized (b) nylon 49 samples.

\subsection{Temperature Evolution on Heating of X-Ray Diffraction Profiles of Nylon 49 Samples Having Different} Initial Structures

The ratio between the different crystalline forms of nylon 49 that can be found at room temperature logically depend on the preparation method as it was observed when the X-ray diffraction patterns of as synthesized and melt crystallized samples were compared. Figure 12 shows additional patterns of samples obtained by solvent casting from a 1,1,1,6,6,6-hexafluoroisopropanol (HFIP) solution, from formic acid solutions at different polymer concentrations and from a melt quenched sample. All samples coming from solution showed a clear peak at $0.375 \mathrm{~nm}$ and a second one in the $0.440-0.428 \mathrm{~nm}$ range, but differences on the their relative ratio (measured as $h_{1} / h_{2}$, being the numerator and the denominator the height of the peaks corresponding to the higher and lower spacings, respectively) were found. Thus, the relative intensity of the lower spacing reflection decreased at the same time that appeared a shoulder (see red arrows in Figure 12) close to $0.42 \mathrm{~nm}$ and related to Form II. Profiles clearly indicated that formation of Form II was favored when HFIP was changed by formic acid and when the polymer concentration in the solution increased. The spectra of the melt quenched sample were clearly different since reflections at 0.42 and 0.375 were overlapped giving rise to a broad signal with a low intensity peak (i.e., Form II was obtained in a greater ratio than in the preceding cases).

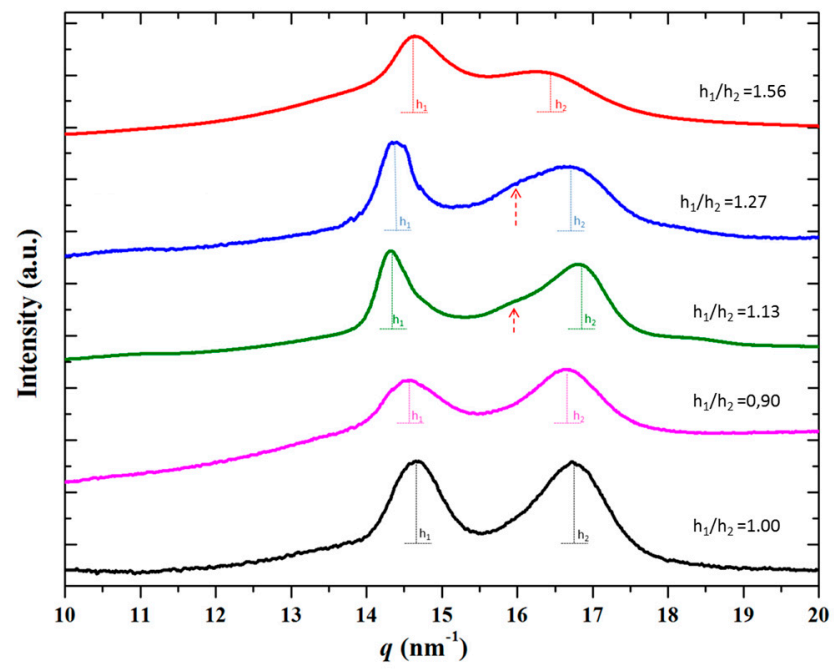

Figure 12. Diffraction profiles of nylon 49 samples taken at room temperature from down to up: as synthesized sample, solvent casting film from HFIP at a polymer concentration of $2 \mathrm{mg} / \mathrm{mL}$, solvent casting film from formic acid at a polymer concentration of $2 \mathrm{mg} / \mathrm{mL}$, solvent casting film from formic acid at a polymer concentration of $10 \mathrm{mg} / \mathrm{mL}$ and a melt quenched sample. 
Figure 13 compares the evolution of diffraction profiles of the different solvent casting films and the melt quenched sample during a heating rate up to fusion. The most relevant feature is that all samples initially having some percentage of Form II displayed a clear transition from Form I to Form II, which appeared clearer for higher Form II contents (e.g., red arrows in the profiles of solvent casting films from formic acid at low and high polymer concentrations). This is obvious for the melt quenched sample, which is characterized by a significant content of Form II. By contrast, the solvent casting film from HIFP showed a similar behavior to that observed for the as synthesized sample. Results point out that samples having only Form I could not structurally transition to Form II, with the presence of Form III being detected only at temperatures close to fusion. More interesting is the finding that the presence of small amounts of Form II enhanced the structural transition. These became potential nuclei that favored the change in the packing arrangement.
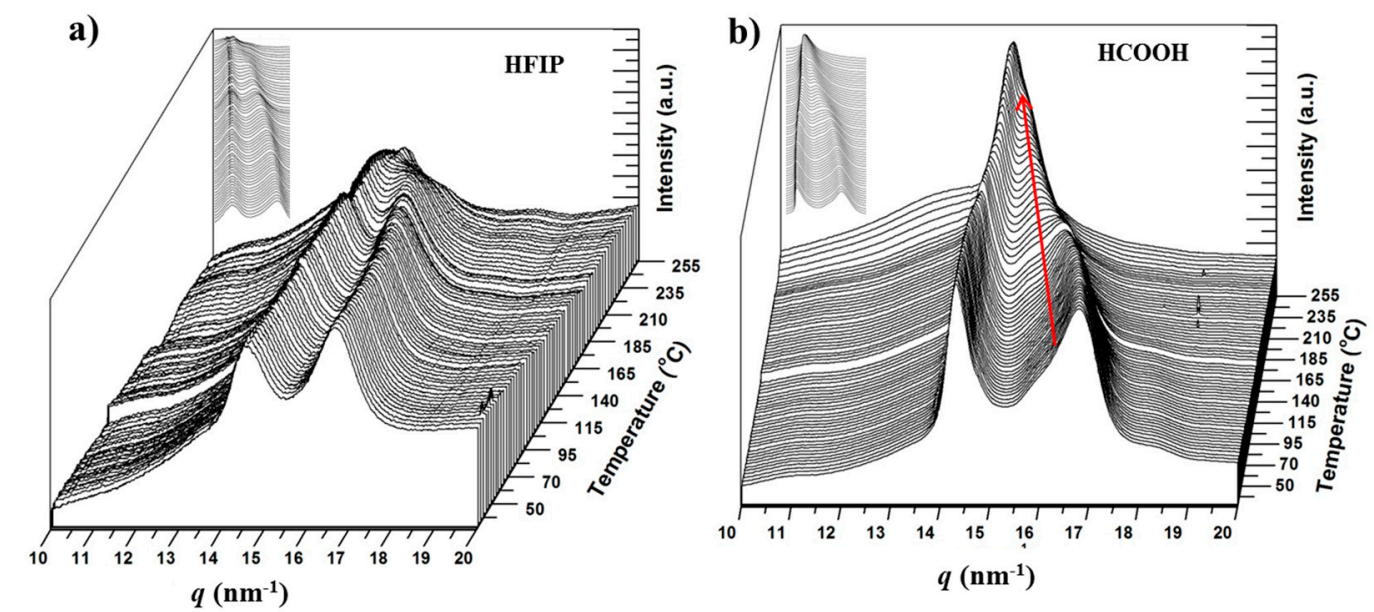

c)

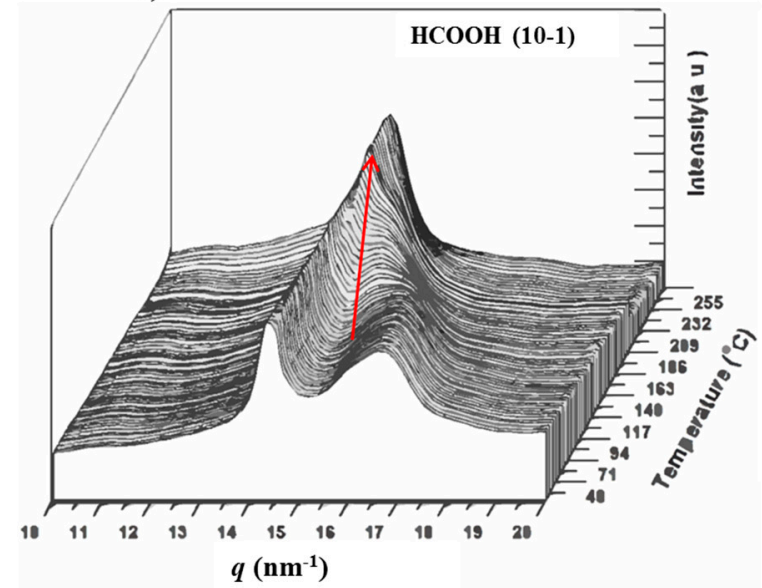

d)

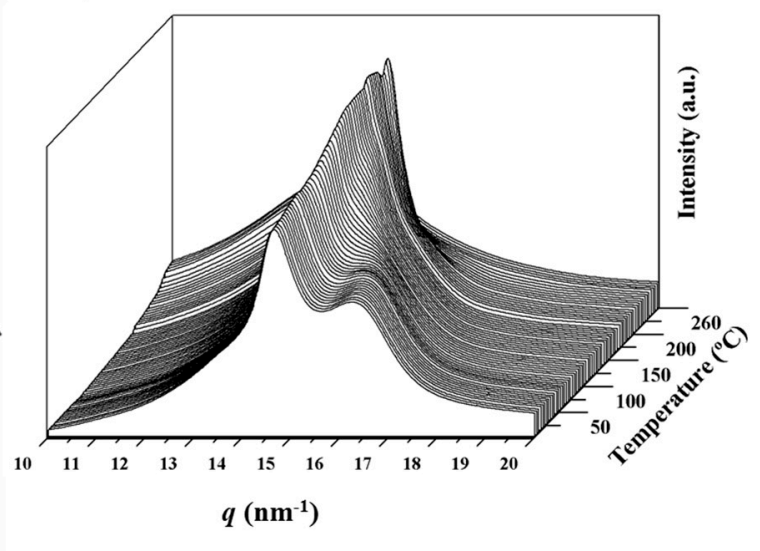

Figure 13. Three dimensional representation of WAXD profiles of nylon 49 during heating $\left(10^{\circ} \mathrm{C} / \mathrm{min}\right)$ from room temperature to fusion for: (a) solvent casting film from HFIP at a polymer concentration of $2 \mathrm{mg} / \mathrm{mL}$; (b) solvent casting film from formic acid at a polymer concentration of $2 \mathrm{mg} / \mathrm{mL}$; (c) solvent casting film from formic acid at a polymer concentration of $10 \mathrm{mg} / \mathrm{mL}$; and (d) melt quenched sample.

\subsection{Thermal Properties of Nylon 49}

DSC heating and cooling runs (Figure 14) revealed a complex thermal behavior of nylon 49 , which is logically linked to the above structural features during non-isothermal treatments. 


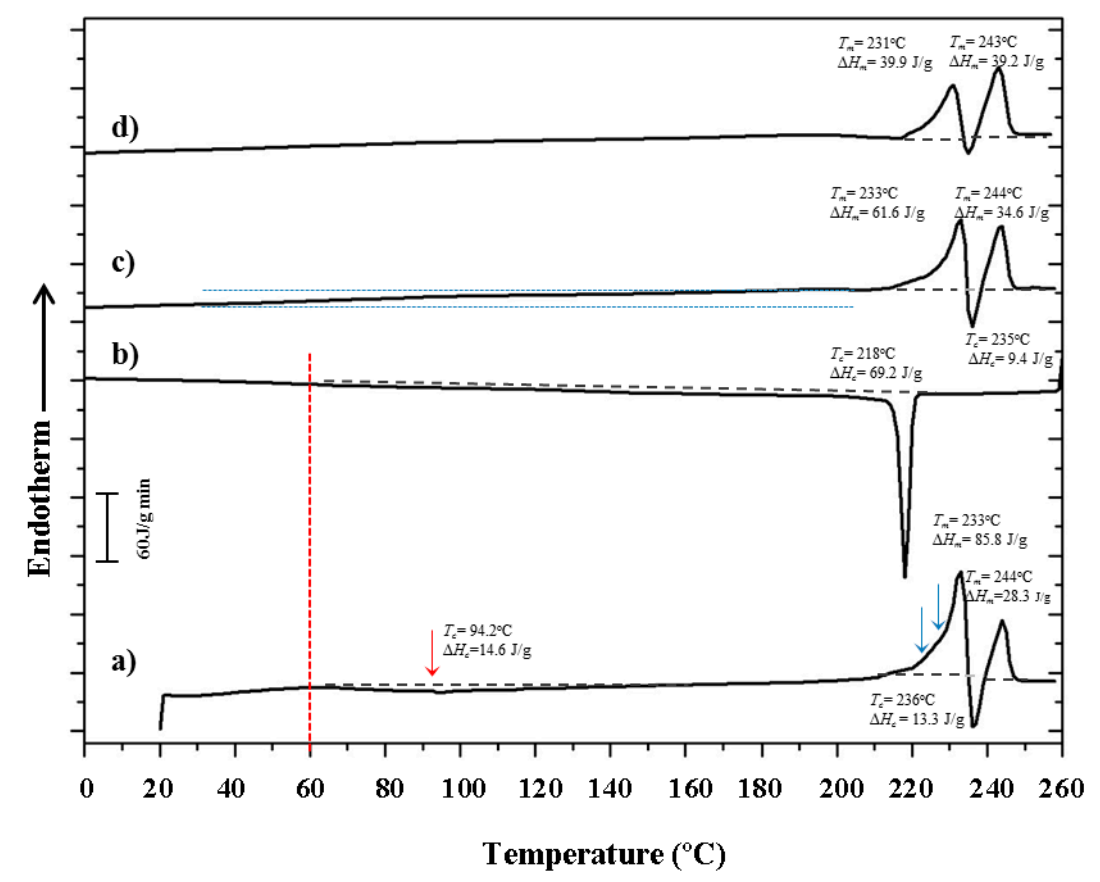

Figure 14. (a) Heating run of the as-synthesized nylon 4 9; (b) cooling run of nylon 49 from the melt state; (c) subsequent heating run of the melt crystallized sample; and (d) heating run from a nylon 49 melt quenched sample. Arrows indicate small endothermic and exothermic peaks.

The following points should be emphasized:

(a) The first heating scan shows two clear endothermic peaks at $233^{\circ} \mathrm{C}$ and $244^{\circ} \mathrm{C}$, which are related to a typical reorganization process where thin lamellae melt and recrystallize, giving rise to thicker crystals. An exothermic peak at an intermediate temperature $\left(236^{\circ} \mathrm{C}\right)$ is also clearly detected and confirms the existence of the indicated reorganization process. According to the synchrotron data, only the high temperature Form III should be involved in the melting and recrystallization processes.

(b) A very broad exothermic peak (red arrow) can also be detected in the first run after the glass transition temperature $\left(50{ }^{\circ} \mathrm{C}\right.$ according to the change of the base line) and up to $150{ }^{\circ} \mathrm{C}$. This process fits with the cold crystallization associated with Form I that was detected in the diffraction profiles (Figures $6 \mathrm{a}$ and $7 \mathrm{a}$ ) during heating.

(c) The first melting peak $\left(233^{\circ} \mathrm{C}\right)$ observed in the first run shows two small shoulders in the low temperature region (blue arrows), which may be related to structural transitions that could involve thin and thick lamellae having the Form I structure, according to the X-ray diffraction data. Therefore, shoulders may correspond to the transition from Form I to Form III for the different lamellar populations. A similar complex process has recently been reported for nylon 6 9 [41]. However, it cannot be ruled out that these endothermic transitions were associated with fusion of Form I lamellae.

(d) The cooling scan is defined by a well-defined exothermic peak at $218^{\circ} \mathrm{C}$ followed by a small and broad exotherm that extends up to a temperature close to $T_{g}$. In this way, the first exotherm corresponds to crystallization into Form III, whereas the subsequent broad exotherm should be linked to the continuous structural transitions (involving Forms I and II) that were detected in the diffraction profiles.

(e) The heating scan of the melt crystallized sample showed the indicated two melting peaks at $233^{\circ} \mathrm{C}$ and $244^{\circ} \mathrm{C}$. The lamellar reordering process seems to be emphasized over that observed in the first heating scan because the relative area of the second melting peak clearly increased. This is 
expected when thin lamellae are less stable due to a worse crystallization process, suggesting that solution crystallized samples have a higher degree of perfection than melt crystallized ones. This conclusion is also in agreement with the differences observed in the global melting enthalpy of both samples (i.e., $85.8+28.3-13.3=100.8 \mathrm{~J} / \mathrm{g}$ and $61.6+34.6-9.4=86.8 \mathrm{~J} / \mathrm{g}$ for solution and melt crystallized samples, respectively). The DSC scan is also characterized by a constant deviation of the base line from $T_{g}$ up to $200{ }^{\circ} \mathrm{C}$, which may be due to the continuous structural transitions detected in the $\mathrm{X}$-ray diffraction profiles during heating. Note also that shoulders before the first melting peak are less relevant for the melt crystallized samples, suggesting that structural transitions took mainly place during the heating process. It is highly relevant that the resultant endothermic enthalpy $(86.8 \mathrm{~J} / \mathrm{g}$ ) associated with the processes occurring at temperatures higher than $200^{\circ} \mathrm{C}$ was clearly higher than the enthalpy associated with the crystallization process performed in the previous scan (i.e., $60 \mathrm{~J} / \mathrm{g}$ for the acute peak and $69.2 \mathrm{~J} / \mathrm{g}$ if the broad exotherm is also considered). This suggests that shoulders of the first melting peak correspond to structural transitions and that the corresponding enthalpies are not associated with melting processes.

(f) The heating scan of the melt quenched sample revealed, again, the above features with differences in the logical decrease of global melting enthalpy $(39.9+39.2-3.2=75.2 \mathrm{~J} / \mathrm{g})$ and the increase of relative intensity of the high temperature melting peak over the low temperature one. In summary, the sample is less crystalline and the reorganization processes become enhanced.

Equilibrium melting temperature $\left(T_{m}{ }^{\circ}\right)$ is a crucial parameter in determining crystal growth rate and specifically degree of supercooling $\left(T_{m}{ }^{\circ}-T_{c}\right)$. The Hoffman-Weeks extrapolation [52] is a commonly accepted method of estimating the equilibrium temperature due to its simplicity and straightforward implementation, although it is subject to criticism [53] and improvements have been proposed [54]. The method is based on Equation (1), which was deduced from a combination of the well-known Gibbs-Thomson equation and secondary nucleation theory [55]. This equation relates the melting temperature, $T_{m}$, of a crystal formed at a temperature $T_{c}$, the equilibrium melting temperature, $T_{m}^{\circ}$, and the thickening coefficient, $\gamma$, defined as the ratio between the thickness of the grown crystal and the initial thickness of a "virgin lamella":

$$
T_{m}=T_{m}^{\circ}(1-(1 / \gamma))+T_{c} / \gamma
$$

A straight line is obtained by plotting $T_{m}$ as a function of $T_{c}$, with the equilibrium temperature corresponding to the intersection of this line with the $T_{m}=T_{c}$ line. The validity of Equation 1 implies that lamellar crystals thicken at a specific crystallization temperature, which also influences the thickening parameter.

Figure 15 shows the complex melting behavior of nylon 49 crystallized at different temperatures. At the lowest temperature $\left(226^{\circ} \mathrm{C}\right)$ only the two crystallization peaks associated with fusion of thin and thick lamellae of nylon 49 in its Form III structure were detected. The predominant melting peak (labeled as peak II) shifted to higher temperatures with the crystallization temperature, allowing the unambiguous estimation of an equilibrium melting temperature of $243^{\circ} \mathrm{C}$ from the Hoffman-Weeks plot (Figure 16). The temperature of the melting peak associated with the thickest lamellae (labeled as peak III) remained practically constant and was practically identical to the estimated equilibrium melting temperature. DSC heating runs also showed a low temperature endothermic peak whose area clearly increased as the crystallization temperature did. A careful interpretation of this behavior is out of the scope of the present work because different processes are involved: isothermal crystallization at the selected temperature and non-isothermal crystallization during the subsequent heating, which could imply structural transitions between the different crystalline forms. It seems that crystallizations performed at the highest temperatures were incomplete and a greater ratio of structures corresponding to Forms II or I was found during the cooling process. Therefore, the area of the lower temperature peak (labeled as peak I) increased. 


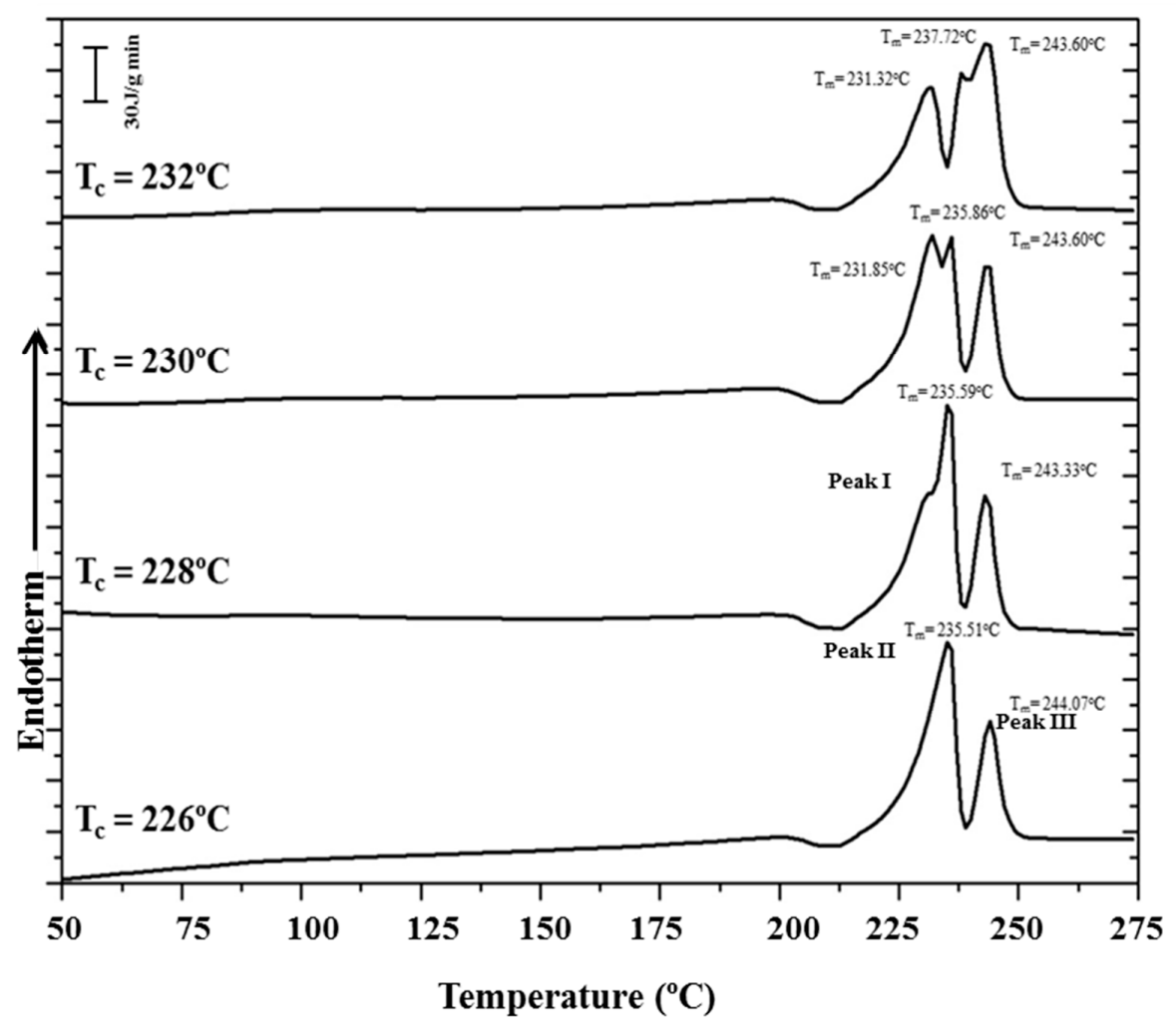

Figure 15. DSC traces corresponding to the heating run of samples isothermally crystallized at the indicated temperatures.

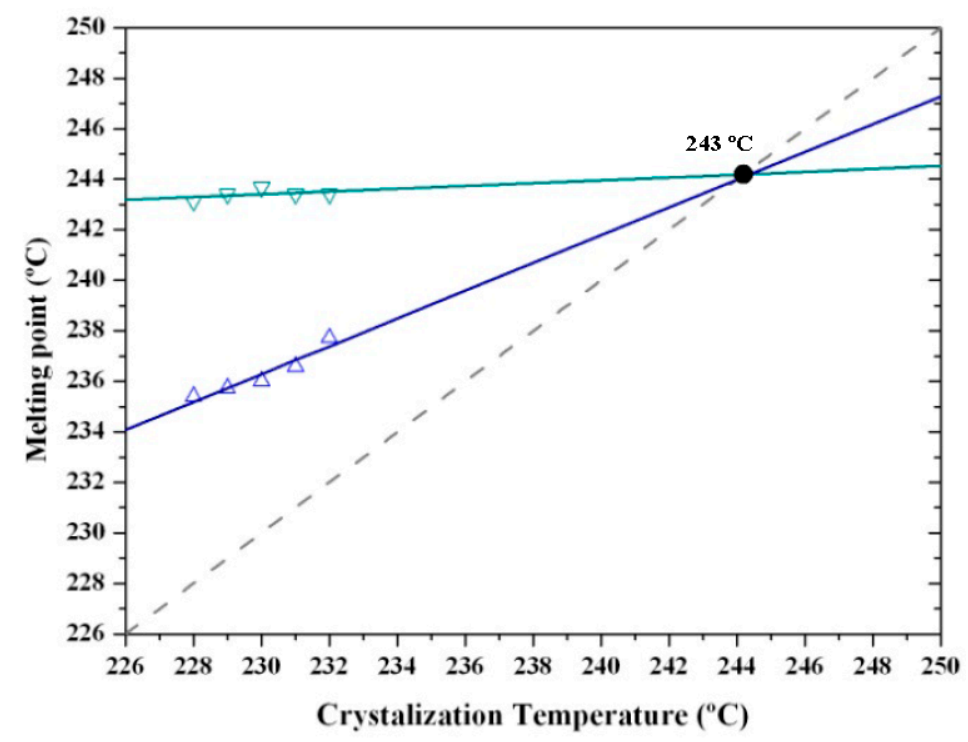

Figure 16. Hoffman-Weeks plot of temperatures corresponding to the observed endothermic Peaks II and III associated with the high temperature Form III versus hot crystallization temperature. An equilibrium melting temperature of $243^{\circ} \mathrm{C}$ could be deduced.

\subsection{Spherulitic Morphologies of Nylon 49 Crystallized from the Melt}

Morphology of spherulites obtained by isothermal crystallization from the melt state depended on the crystallization temperature, as shown in Figure 17 for different representative temperatures. The number of active nuclei increased with decreasing crystallization temperatures, and logically 
the size of spherulites decreased. Thus, diameters close to $200 \mu \mathrm{m}$ and $25 \mu \mathrm{m}$ were characteristic of spherulites obtained at 238 and $229^{\circ} \mathrm{C}$. Significant changes were detected despite the narrow crystallization temperature range (i.e., $9{ }^{\circ} \mathrm{C}$ ). At the highest temperature, axialitic entities with complex birefringence and including domains with well-formed planar crystals (see dashed ellipsoids) were characteristic. At the lowest temperature, only ringed spherulites with a clearly negative birefringence were usually detected. At intermediate temperatures (e.g., $235^{\circ} \mathrm{C}$ and $233^{\circ} \mathrm{C}$ ), spherulites showed a speckled texture, being detected incipient rings and a confusing birefringence at $233^{\circ} \mathrm{C}$. The predominant negative birefringence observed for nylon 49 spherulites contrasts with the positive sign characteristic of conventional nylons that is attained at low crystallization temperature and has been associated to a radial disposition of the single hydrogen bonding direction.

X-ray diffraction profiles taken in the narrow temperature interval between 238 and $229{ }^{\circ} \mathrm{C}$ corresponded to the single high temperature pseudohexagonal molecular arrangement (Form III). Thus, the differences observed in morphology and texture are not related to a change on the crystalline structure. Nevertheless, it should be considered that micrographs were taken at room temperature and consequently optical properties should be related to the predominant Form I that was achieved during cooling as deduced from synchrotron data. Electron diffraction patterns taken at room temperature of thin spherulites crystallized in the above temperature interval reflect slight variations considering the symmetry of the pattern (Figure 18). Note that lamellar twisting varied, being more difficult to obtain symmetric $h k 0$ diffraction patterns at the lower temperature. Figure 18 shows the predominant electron diffraction pattern obtained from spherulites crystallized at $229^{\circ} \mathrm{C}$ and $238^{\circ} \mathrm{C}$.
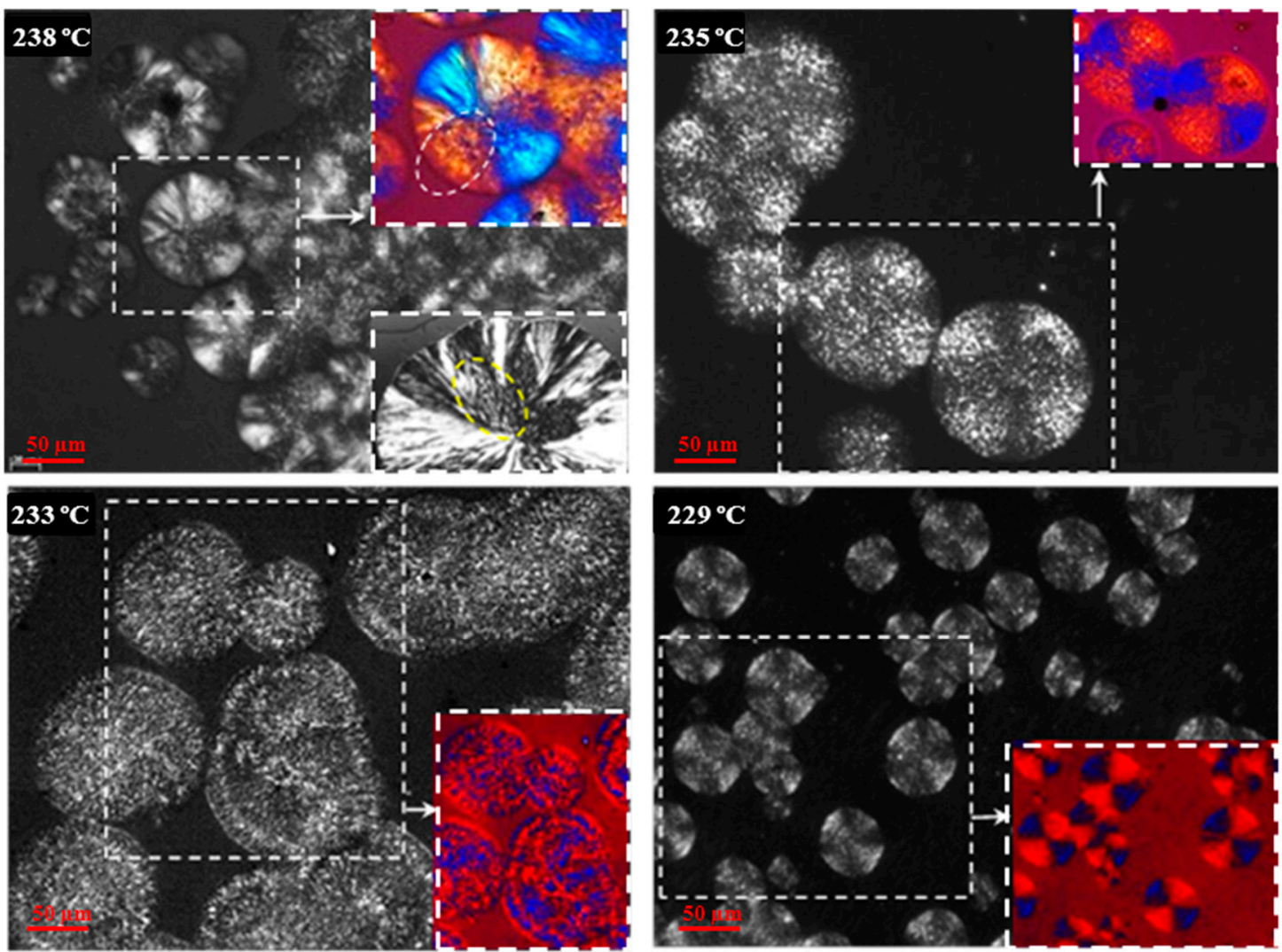

Figure 17. Typical spherulitic morphologies of nylon 49 isothermally crystallized at the indicated temperatures. Black and white inset of the micrograph taken at $238{ }^{\circ} \mathrm{C}$ reveals the complex internal structure of the obtained spherulites. Color micrographs taken with a red tin plate to determine the sign of birefringence are shown as insets for all crystallizations. 

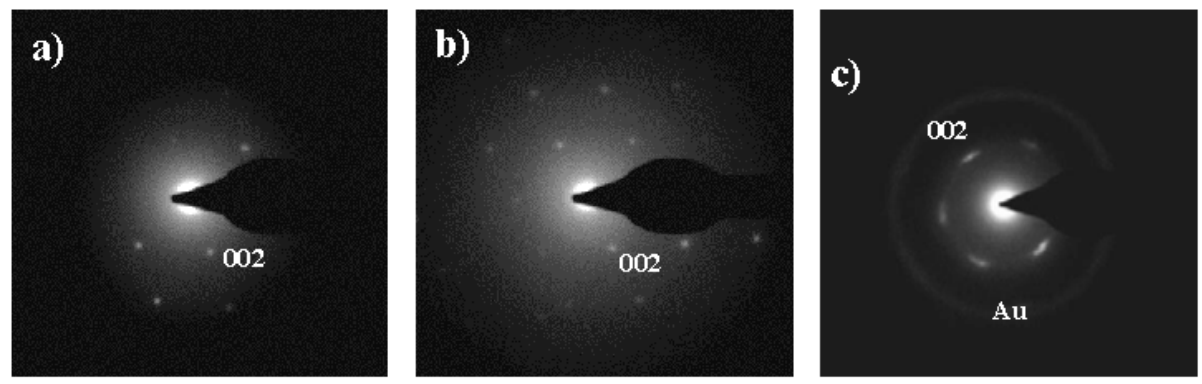

Figure 18. Selected-area electron diffraction pattern of nylon 49 spherulites crystallized at: $229^{\circ} \mathrm{C}(\mathbf{a}, \mathbf{b})$; and $238^{\circ} \mathrm{C}$ (c). Patterns corresponded to the low temperature structure observed from solution crystallized samples. Symmetry is usually lost in the patterns coming from spherulites crystallized at $229^{\circ} \mathrm{C}(\mathbf{a})$ as consequence of lamellar twisting, although a $2 \mathrm{~mm}$ symmetry can also hardly detected (b). This symmetry is more easily observed from spherulites attained at the higher temperature as a consequence of a flat-on lamellar disposition (c).

Kinetics of crystallization of nylon 49 from the melt was studied by optical microscopy. Spherulite radius grew linearly with time until impingement (not shown). Crystal growth rate $(G)$ was determined in the studied temperature interval where measurable spherulites formed.

Primary nucleation density increased dramatically with decreasing temperatures (i.e., 80 nuclei $/ \mathrm{mm}^{2}$ and 1600 nuclei $/ \mathrm{mm}^{2}$ were determined at $238^{\circ} \mathrm{C}$ and $229^{\circ} \mathrm{C}$, respectively), and, consequently, the available temperature range for kinetic studies was highly limited. Micrographs taken during crystallization at the highest temperature showed that crystallization was mainly athermic since the number of nuclei was kept constant over time.

Secondary nucleation constants were determined by the Lauritzen-Hoffman equation [56]:

$$
G=G_{0} \times \exp \left[-U^{*} /\left(R\left(T_{\mathcal{c}}-T_{\infty}\right)\right)\right] \times \exp \left[-K_{g} /\left(T_{\mathcal{c}}(\Delta T) f\right)\right]
$$

where $G_{0}$ is the constant pre-exponential factor, $U^{*}$ is the activation energy characteristic of the transport of crystallizing segments across the liquid-crystal interface, $T_{\infty}$ is the temperature below which such motion ceases, $R$ is the gas constant, $K_{g}$ is the corresponding secondary nucleation constant, $\Delta \mathrm{T}$ is the degree of supercooling measured as $T_{m}-T_{\mathcal{c}}$ (where $T_{m}$ is the equilibrium melting temperature and $T_{\mathcal{c}}$ is the crystallization temperature), and $f$ is a correction factor accounting for the variation in the bulk melting enthalpy per unit volume with temperature $\left(f=2 T_{c} / T_{m}+T_{c}\right)$.

The inset of Figure 19 shows the linear plots obtained using $U^{*}$ and $T_{\infty}$ parameters of $1600 \mathrm{cal} / \mathrm{mol}$ and $T_{g}-35 \mathrm{~K}$, respectively. It is clear that two crystallization regimes defined by secondary nucleation constants of $0.33 \times 10^{5} \mathrm{~K}^{2}$ and $0.15 \times 10^{5} \mathrm{~K}^{2}$ fit the experimental data. Regimes III and II could be assumed since the experimental ratio between slopes (2.2) was close to the theoretical $K_{g}{ }^{I I I} / K_{g}{ }^{I I}$ value of 2 . Figure 19 also corroborates that the two bell-shaped curves calculated by the Lauritzen-Hoffman equations fit well with the experimental spherulitic growth data. 


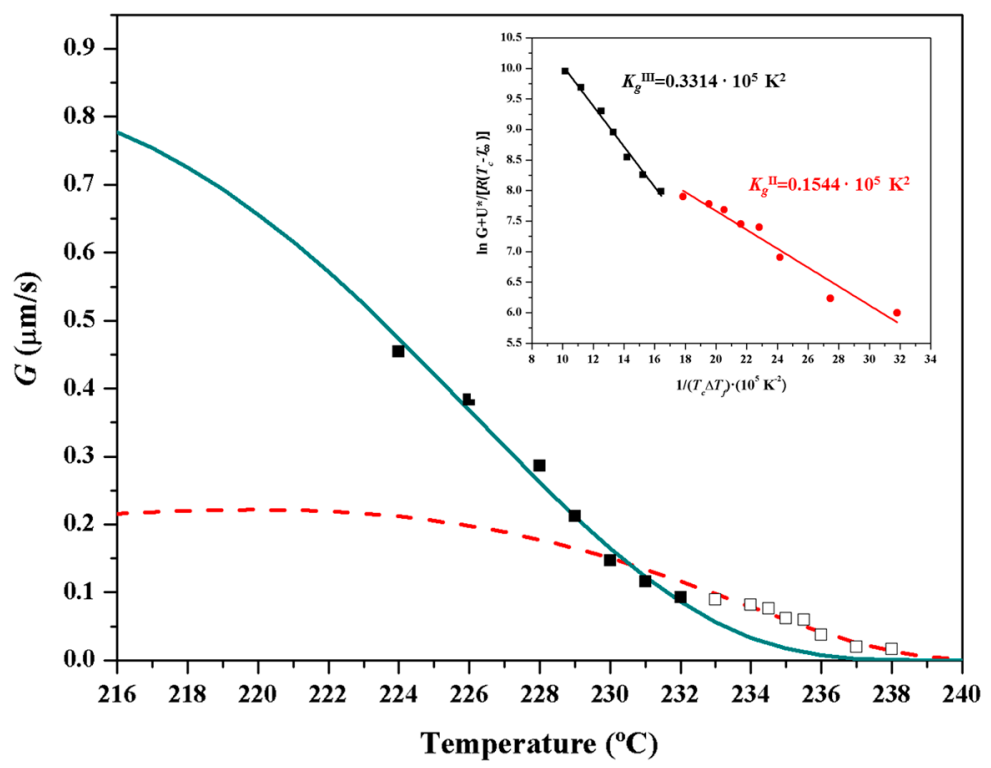

Figure 19. Temperature dependence of crystal growth rate (solid green line for Regime III and dashed red line for Regime II) determined by Lauritzen-Hoffman equation and using the best fit parameters deduced for the two crystallization regimes. Experimental crystal growth rates and indicated by the square symbols. The inset shows the plot of $\ln G+U^{*} / R\left(T_{c}-T_{\infty}\right)$ versus $1 / T_{c}(\Delta T) f$ to determine the $\mathrm{Kg}$ secondary nucleation parameters.

\section{Conclusions}

Nylon 49 crystallized from diluted glycerin solutions giving rise to lamellar single crystals which morphology varied according to the crystallization temperature. Specifically, regular rhombic crystals were attained at $120^{\circ} \mathrm{C}$, while aggregates or irregular and elongated crystals were characteristics of lower and higher temperatures, respectively. Electron diffraction patterns showed a $2 \mathrm{~mm}$ symmetry and pointed out a single structure (Form I) characterized by a disposition of hydrogen bonds along two planar orientations as reported for other even-odd nylons previously studied.

Nylon 49 isothermally crystallized from the melt giving rise to spherulites with a texture that clearly varied in a very narrow temperature interval (i.e., from $238{ }^{\circ} \mathrm{C}$ to $229{ }^{\circ} \mathrm{C}$ ). Flat-on and edge-on lamellar dispositions were detected at the highest and the lowest crystallization temperatures, changing the morphology from axialites to ringed spherulites and the formation of speckled spherulites at intermediate temperatures. Electron diffraction patterns indicate that all these spherulites predominantly had the Form I structure when were observed at room temperature. At this temperature, the birefringence sign was negative in contrast with the positive sign detected for conventional even-even polyamides. Crystallization kinetic analysis indicated that two crystallization regimes were characteristic of nylon 49 , being the involved temperatures in agreement with the observed morphologic changes.

Nylon 49 showed complex transitions during heating and cooling processes that depended on the way as the sample was prepared. Before melting, nylon 49 achieved a typical pseudohexagonal arrangement (Form III) that was consequence of the named Brill transition. A new polymorphic structure (II) appeared during crystallization from the melt as well as from crystallization from some specific solvents. Temperature evolution of diffraction patterns during heating processes was clearly dependent on the presence of Form II. Thus, profiles indicate a direct transition from Form I to Form III or from Form I to Form II when traces of the intermediate structure (Form II) were absent or present, respectively. The complex behavior was also supported by calorimetric and spectroscopic data, being of interest for the understanding/racionalization of the high structural variability described for nylons in general and even the differences detected between even-odd nylons in particular. 
Acknowledgments: The authors acknowledge support from MINECO and FEDER (MAT2015-69547-R), and the Generalitat de Catalunya (2014SGR188). Diffraction experiments were performed at NCD beamline at ALBA Synchrotron with the collaboration of ALBA staff.

Author Contributions: Cristian Olmo performed experiments; María Teresa Casas performed electron microscopy studies; Lourdes Franco was involved in thermal characterization and acquisition of synchrotron data; Juan Carlos Martínez contributed in the discussion of synchrotron experiments; and Jordi Puiggalí supervised project direction and wrote the paper.

Conflicts of Interest: The authors declare no conflict of interest.

\section{References}

1. Kohan, M.I. Nylon plastics handbook; Hanser Publishers: Munich, Germany, 1995; Volume 1, pp. 1-11.

2. Marchildon, K. Polyamides—Still Strong After Seventy Years. Macromol. React. Eng. 2011, 5, 5-22. [CrossRef]

3. Bunn, C.W.; Garner, E.V. The crystal structure of two polyamides (Nylons). Proc. R. Soc. London Ser. A. 1947, 189, 39-68. [CrossRef]

4. Holmes, D.E.; Bunn, C.W.; Smith, D. The crystal structure of polycaproamide: Nylon 6. J. Polym. Sci. Part A: Gen. Pap. 1955, 17, 159-177. [CrossRef]

5. Prieto, A.; Montserrat, J.M.; Muñoz-Guerra, S. Structure of nylon 7 solution grown crystal. J. Mater. Sci. 1990, 25, 2091. [CrossRef]

6. Dasgupta, S.; Hammond, W.B.; Goddard, W.A. Crystal Structures and Properties of Nylon Polymers from Theory. J. Am. Chem. Soc. 1996, 118, 12291. [CrossRef]

7. Urpí, L.; Villaseñor, P.; Rodríguez-Galán, A.; Puiggalí, J. Crystal structure of N,N'-dipropylsuberamide and $\mathrm{N}, \mathrm{N}^{\prime}$-dipropylsebacamide as a packing model of the a-form of even-even nylons. Macromol. Chem. Phys. 2000, 201, 1726-1731.

8. Owen, A.J.; Kollross, P. A note on the crystal structure of nylon 12. Polym. Commun. 1983, 24, 303.

9. Arimoto, H.; Ishibashi, M.; Irai, M.; Chatani, Y. Crystal structure of the $\gamma$-form of nylon 6. J. Polym. Sci. A 1965, 3, 317. [CrossRef]

10. Kinoshita, Y. An investigation of the structures of polyamide series. Makromol. Chem. 1959, 33, 1. [CrossRef]

11. Kawaguchi, A.; Ikawa, T.; Fujiwara, Y.; Tabuchi, M.; Monobe, K. Polymorphism in lamellar single crystals of nylon 11. J. Makromol. Sci. phys. 1981, B20, 1. [CrossRef]

12. Brill, R. Beziehungen zwischen wasserstoffbindung und einigen eigenschaften von polyamiden. Makromol. Chem. 1956, 18, 294-309. [CrossRef]

13. Wendoloski, J.J.; Gardner, K.H.; Hirschinger, J.; Miura, H.; English, A.D. Molecular dynamics in ordered structures: computer simulation and experimental results for nylon 66 crystals. Science 1990, 247, 431-436. [CrossRef] [PubMed]

14. Feldman, A.Y.; Wachtel, E.; Vaughan, G.B.M.; Weinberg, A.; Marom, G. The Brill Transition in transcrystalline Nylon-66. Macromolecules 2006, 39, 4455-4459. [CrossRef]

15. Nair, S.S.; Ramesh, C.; Tashiro, K. Crystalline phases in nylon-11: studies using HTWAXS and HTFTIR. Macromolecules 2006, 39, 2841-2848. [CrossRef]

16. Wolanov, Y.; Feldman, A.Y.; Harel, H.; Marom, G. Amorphous and crystalline phase interaction during the Brill transition in nylon 66. Express Polym. Lett. 2009, 3, 452-457. [CrossRef]

17. Wang, C.; Tsou, S.Y.; Lin, H.S. Brill transition of nylon-6 in electrospun fibers. Colloid Polym. Sci. 2012, 290, 1799-1809. [CrossRef]

18. Suzuki, H.; Ishii, S.; Sato, H.; Yamamoto, S.; Morisawa, Y.; Ozaki, Y.; Uchiyama, T.; Otani, C.; Hoshina, H. Brill transition of nylon- 6 characterized by low-frequency vibration through terahertz absorption spectroscopy. Chem. Phys. Lett. 2013, 575, 36-39. [CrossRef]

19. Franco, L.; Navarro, E.; Subirana, J.A.; Puiggalí, J. Synthesis and structure of nylons 1,n. Macromolecules 1994, 27, 4284-4297. [CrossRef]

20. Puiggalí, J.; Aceituno, J.E.; Navarro, E.; Campos, L.; Subirana, J.A. Structure of n,3 polyamides, a group of nylons with two spatial hydrogen-bond orientations. Macromolecules 1996, 29, 8170-8179. [CrossRef]

21. Bella, J.; Puiggalí, J.; Subirana, J.A. Glycine residues induce a helical structure in polyamides. Polymer 1994, 35, 1291-1297. [CrossRef]

22. Navarro, E.; Puiggalí, J.; Subirana, J.A. Study of 1,4-bis(propylaminomalonylamino)butane as a model compound for nylons n,3. Macromol. Chem. 1995, 7, 2361-2370. [CrossRef] 
23. Tereshko, V.; Navarro, E.; Puiggalí, J.; Subirana, J.A. Structures of two malonamide derivatives as models of nylons n,3 and of peptidomimetic compounds. Macromolecules 1993, 26, 7024-7028. [CrossRef]

24. Tormo, J.; Puiggalí, J.; Vives, J.; Fita, I.; Lloveras, J.; Bella, J.; Aymamí, J.; Subirana, J.A. Crystal structure of a helical oligopeptide model of polyglycine II and of other polyamides: Acetyl-(glycil-b-alanyl) ${ }_{2}-\mathrm{NH}$ propyl. Biopolymers 1992, 32, 643-648. [CrossRef] [PubMed]

25. Morales-Gámez, L.; Ricart, A.; Franco, L.; Puiggalí, J. Study on the brill transition and melt crystallization of nylon 65: A polymer able to adopt a structure with two hydrogen-bonding directions. Eur. Polym. J. 2010, 46, 2063-2077. [CrossRef]

26. Villaseñor, P.; Franco, L.; Subirana, J.A.; Puiggalí, J. On the crystal structure of odd-even nylons: polymorphism of nylon 5,10. J. Polym. Sci. Part B: Polym. Phys. 1999, 37, 2383-2395. [CrossRef]

27. Franco, L.; Subirana, J.A.; Puiggalí, J. Structure and Morphology of Odd Polyoxamides [Nylon 9,2]. A New Example of Hydrogen-Bonding Interactions in Two Different Directions. Macromolecules 1998, 31, 3912-3924. [CrossRef]

28. Nakagawa, K.; Nozaki, S.; Maeda, T.; Yamamoto, T. Polymorphism of poly (nonamethyleneoxamide) crystal. Polymer 2015, 57, 99-104. [CrossRef]

29. Cui, X.; Yan, D. Preparation, characterization and crystalline transitions of odd-even polyamides 11,12 and 11,10. Eur. Polym. J. 2005, 41, 863-870. [CrossRef]

30. Samanta, S.; He, J.; Selvakumar, S.; Lattimer, J.; Ulven, C.; Sibi, M.; Bahr, J.; Chisholm, B.J. Polyamides based on the renewable monomer, 1,13- tridecanediamine II: synthesis and characterization of nylon 13,6. Polymer 2013, 54, 1141-1149. [CrossRef]

31. Morales-Gámez, L.; Soto, D.; Franco, L.; Puiggalí, J. Brill transition and melt crystallization of nylon 56 an odd-even polyamide with two hydrogen-bonding directions. Polymer 2010, 51, 5788-5798. [CrossRef]

32. Navarro, E.; Subirana, J.A.; Puiggalí, J. The structure of nylon 12,5 is characterized by two hydrogen bond directions as are other polyamides derived from glutaric acid. Polymer 1997, 38, 3429-3432. [CrossRef]

33. Cui, X.; Yan, D.; Xiao, C. Synthesis and characterization of novel polyamides based on tridecanedioic acid: Nylons 3 13, 5 13, 613, 7 13, 9 13, 10 13, 11 13. e-Polym 2004, 4, 68. [CrossRef]

34. Morales-Gámez, L.; Casas, M.T.; Franco, L.; Puiggalí, J. Structural transitions of nylon 47 and clay influence on its crystallization behavior. Eur. Polym. J. 2013, 49, 1354-1364. [CrossRef]

35. Franco, L.; Cooper, S.J.; Atkins, E.D.T.; Hill, S.J.; Jones, N.A. Nylon 69 can crystallize with hydrogen bonding in two and in three interchain directions. Macromolecules 1998, 36, 1153-1165.

36. Murase, S.; Casas, M.T.; Martínez, J.C.; Estrany, F.; Franco, L.; Puiggalí, J. Reversible changes induced by temperature in the spherulitic birefringence of nylon 6 9. Polymer 2015, 76, 34-45. [CrossRef]

37. Olmo, C.; Rota, R.; Martínez, J.C.; Puiggalí, J.; Franco, L. Temperature-induced structural changes in even-odd nylons with long polymethylene segments. J. Polym. Sci. Part B, Polym. Phys. 2016, 54, 2494-2506. [CrossRef]

38. van Veltoven, J.L.J.; Gootjes, L.; Noordover, B.A.J.; Meuldjk, J. Bio-based, amorphous polyamides with tunable properties. Eur. Polym. J. 2015, 66, 57-66. [CrossRef]

39. Jasinska, L.; Villani, M.; Wu, J.; van Es, D.V.; Klop, E.; Rastogi, S. Novel, fully biobased semicrystalline polyamides. Macromolecules 2011, 44, 3458-3466. [CrossRef]

40. Gandini, A.; Lacerda, T.M.; Carvalho, A.J.F.; Trovatti, E. Progress of Polymers from Renewable Resources: Furans, Vegetable Oils, and Polysaccharides. A Chem. Rev. 2016, 116, 1637-1669. [CrossRef] [PubMed]

41. Winnacker, M.; Sag, J. Sustainable terpene-based polyamides via anionic polymerization of a pinene-derived lactam. Chem. Commun. 2018, 54, 841-844. [CrossRef] [PubMed]

42. Eltahir, Y.A.; Saeed, H.A.M.; Haroon, A.M.; Chen, Y.J.; Xia, Y.M.; Wang, Y.M. Effect of hot drawing on the structure and properties of novel polyamide 5,6 fibers. Text. Res. J. 2014, 84, 1700-1707. [CrossRef]

43. Eltahir, Y.A.; Saeed, H.A.M.; Yuejun, C.; Xia, Y.; Yimin, W. Parameters characterizing the kinetics of the non-isothermal crystallization of polyamide 5,6 determined by differential scanning calorimetry. J. Polym. Eng. 2014, 34, 353-358. [CrossRef]

44. Jiang, J.D.; Zhang, K.; Liu, C.Y.; Wu., G.Z. Thermal expansion behavior of aliphatic polyamides. Acta Polym. Sin. 2013, 2, 255-262.

45. Li, Y.L.; Hao, X.M.; Guo, Y.F.; Chen, X.; Yang, Y.; Wang, J.M. Study on the acid resistant properties of bio-based nylon 56 fiber compared with the fiber of nylon 6 and nylon 66. Adv. Mater. Res. 2014, 1048, 57-61. [CrossRef]

46. Capsal, J.F.; Dantras, E.; Dandurand, J.; Lacabanne, C. Dielectric relaxations and ferroelectric behviour of even-odd polyamide PA 6,9. Polymer 2010, 51, 4606-4610. [CrossRef] 
47. Liu, S.; Cui, Z.; Fu, P.; Liu, M.; Zhang, L.; Li, Z.; Zhao, Q. Ferroelectric behavior and polarization mechanism in odd-odd polyamide 11,11. J. Polym. Sci. Part B Polym. Phys. 2014, 52, 1094-1099. [CrossRef]

48. Scheinbeim, J.J.; Lee, J.W.; Newman, B.A. Ferroelectric Polarization Mechanisms in Nylon 11. Macromolecules 1992, 25, 3729-3732. [CrossRef]

49. Lovinger, A.J. Crystallographic factors affecting the structure of polymeric spherulites I. Morphology of directionally solidified polyamides. J. Appl. Phys. 1978, 49, 5003-5013. [CrossRef]

50. Lovinger, A.J. Crystallographic factors affecting the structure of polymeric spherulites II. X-ray diffraction of solidified polyamides and general conclusion. J. Appl. Phys. 1978, 49, 5014-5028. [CrossRef]

51. Magill, J.H. Formation of spherulities in polyamides. IV. Even-odd polyamides and poly $(\omega$-aminocarboxylic acids). J. Polym. Sci. Part A-2 Polym. Phys. 1969, 7, 123-142. [CrossRef]

52. Hoffman, J.D.; Weeks, J.J. Melting process and the equilibrium melting temperature of polychlorotrifluoroethylene. J. Res. Natl. Bur. Stand. 1962, 66A, 13-28. [CrossRef]

53. Strob, G. From the melt via mesomorphic and granular crystalline layers to lamellar crystallites: a major route followed in polymer crystallization? Eur. Polym. J. 2000, E3, 165-183.

54. Marand, H.; Xu, J.; Srinivas, S. Determination of the equilibrium melting temperature of polymer crystals: linear and nonlinear Hoffman-Weeks extrapolations. Macromolecules 1998, 31, 8219-8229. [CrossRef]

55. Hoffman, J.D.; Davies, G.T.; Lauritzen, J.D.; Hannay, N.B. (Eds.) Treatise on Solid State Chemistry; Plenum Press: New York, NY, USA, 1976; Volume 7, pp. 497-614.

56. Lauritzen, J.I.; Hoffman, J.D. Extension of theory of growth of chain-folded polymer crystals to large undercoolings. J. Appl. Phys. 1973, 44, 4340-4352. [CrossRef]

(C) 2018 by the authors. Licensee MDPI, Basel, Switzerland. This article is an open access article distributed under the terms and conditions of the Creative Commons Attribution (CC BY) license (http:/ / creativecommons.org/licenses/by/4.0/). 